\title{
Periodically synchronously coupled integrations with the atmosphere-ocean general circulation model ECHAM3/LSG
}

Received: 18 February 1997/Accepted: 27 October 1997

\begin{abstract}
A new periodically synchronous coupling scheme has been applied to an atmosphere-ocean general circulation model. Due to a temporary switching off of the atmospheric model this scheme can considerably reduce computer requirements of coupled model experiments. In order to evaluate the new coupling scheme the model results are compared to corresponding synchronously coupled integrations. Experiments with fixed present-day $\mathrm{CO}_{2}$ concentration and a gradual increase of $\mathrm{CO}_{2}$ show a good reproduction of the mean state and the climate-change pattern, respectively. The deviations from the synchronously coupled experiments are in the range of the variability of the corresponding synchronously coupled runs. Due to the forcing during the ocean-only periods the short-term fluctuations are underestimated and the long-term variability is overestimated.
\end{abstract}

\section{Introduction}

Coupled atmosphere-ocean general circulation models (AOGCMs) are characterized by a high utilization of computer resources. A potential method to reduce the computer requirements is the simplification or reduction of the physical processes which are implemented in the coupled model. Furthermore, the spatial resolution of the model can be reduced. Both methods could lead to a remarkable lowering of the quality of the model results. Another possibility is the saving of computer resources due to a temporary switching off of the atmo-

R. Voss $(\square) \cdot$ U. Cubasch

Deutsches Klimarechenzentrum, Bundesstr. 55, D-20146 Hamburg, Germany

E-mail: reinhard.voss@dkrz.de

R. Sausen

Institut für Physik der Atmosphäre, DLR Oberpfaffenhofen,

D-82234 Weßling, Germany spheric component during the simulation. This method is usually very effective, as the atmospheric component of most AOGCMs utilizes the greater part of the computer resources. This approach is enabled by the different characteristic time scales of both model components: the atmosphere adjusts much faster to changes of the boundary conditions than the oceanic component does.

Coupling methods with reduced simulation periods of the atmosphere, the asynchronous and periodically synchronous coupling methods, have been investigated by Sausen and Voss (1996; hereafter cited as SV. Due to a printing error, Fig. 11 of this paper is wrong. The correct version of this figure is displayed in an Erratum in this issue, p. 305) using a simple energy-balance model. Previously developed versions of these coupling methods fail if the coupled model produces high internal variability. Since this desired feature is present in most AOGCMs, Voss and Sausen (1996; hereafter cited as VS) developed a periodically synchronous coupling scheme which is suitable for these models. This scheme was also tested by means of SV's simple energy-balance model.

The profit resulting from reducing computation time is most important for AOGCMs as their application is often restricted by the considerable utilization of computer resources. Therefore, it is necessary to check whether the new coupling scheme can also be successfully applied in the case of these more comprehensive models. In order to test the performance of the periodically synchronous coupling scheme of VS, a set of experiments with the AOGCM ECHAM3/LSG has been performed. The atmospheric component of this coupled model consists of the general circulation model ECHAM3 (Roeckner et al. 1992) with a T21 horizontal resolution. The Large-Scale Geostrophic ocean model (LSG; Maier-Reimer et al. 1993), with a grid fitted to the Gaussian grid of the atmospheric model, represents the oceanic component. This coupled model has been used in a number of synchronously and periodically 
synchronously coupled climate-change experiments (e.g. Hegerl et al. 1997; Schiller et al. 1997).

In order to estimate the quality of the periodically synchronous coupling scheme, the results are compared to corresponding synchronously coupled experiments. In the synchronously coupled simulations, both model components are integrated quasi-simultaneously over the full simulation period. One pair of 500-y simulations was performed with constant present-day $\mathrm{CO}_{2}$ concentration. In a second case, the $\mathrm{CO}_{2}$ concentration gradually increases until the $\mathrm{CO}_{2}$ doubling is reached after $60 \mathrm{y}$. The $\mathrm{CO}_{2}$ content remains constant for the following years. These climate-change simulations were integrated over $150 \mathrm{y}$. The experiments with constant $\mathrm{CO}_{2}$ concentration were analyzed in view of the mean states and the climate variability. The transient behaviour and the climate-change patterns were compared for the greenhouse-gas simulations.

The individual model components and their coupling are presented in Sect. 2. In Sect. 3 the experiments performed with the synchronously and periodically synchronously coupled model versions are described. The analysis of the experiments with constant $\mathrm{CO}_{2}$ concentration is given in Sect. 4, and the climatechange integrations are compared in Sect. 5. Finally, the results are summarized and conclusions are drawn in Sect. 6.

\section{The coupled model}

\subsection{The atmospheric model}

The atmospheric component of the coupled model consists of the general circulation model ECHAM3 (Roeckner et al. 1992). This spectral model is based on the primitive equations. The prognostic variables are vorticity, divergence, temperature, surface pressure, humidity, and cloud liquid water. Radiation, cloud formation, precipitation, convection, vertical and horizontal diffusion are parametrized. The spectral model is here used in a T21 horizontal resolution. The corresponding resolution of the Gaussian grid is approx. $5.6^{\circ} \times 5.6^{\circ}$. Vertically, the model is discretized in 19 levels up to a pressure level of $10 \mathrm{hPa}$. A time step of 40 minutes is applied. The annual and daily cycles of the solar radiation are included.

In addition to the standard version, the river run-off into the ocean is simulated (Sausen et al. 1994). In the uncoupled mode, sea surface temperatures (SSTs) and the sea-ice distribution are prescribed as boundary conditions.

\subsection{The oceanic model}

The Large-Scale Geostrophic ocean general circulation model LSG (Maier-Reimer et al. 1993), which is the oceanic component of the coupled model, is also based on the primitive equations. The advection of momentum is neglected. Horizontally, LSG is discretized on a $5.6^{\circ} \times 5.6^{\circ}$ E-type grid (Arakawa and Lamb 1977) which matches the Gaussian grid of the atmospheric model. In the vertical the model is subdivided into 11 layers. A simple thermodynamic sea-ice model is included.

The time step of the model version used in this study is 30 days, except for the thermodynamics of the uppermost layer. In order to avoid a phase error with the atmospheric model and instabilities of the sea-ice formation in the coupled mode, a time step of one day is used for the uppermost ocean layer. This step contains the calculation of ice thickness, temperature and salinity. The boundary conditions of the standard version of the uncoupled LSG are given by distributions of wind stress, near-surface air temperature and salinity.

\subsection{The synchronous coupling}

In the coupled model the atmosphere-ocean fluxes of heat, fresh water, and momentum (wind stress), which are calculated in the atmospheric sub-model, serve as forcing for the oceanic model (Fig. 1; the data bank is out of use in the synchronously coupled model). All three quantities are flux corrected (Sausen et al. 1988). This method is used to avoid a possible strong climate drift. Applying the flux-correction technique means that both sub-models are coupled by the anomalies of the fluxes relative to the equilibrium state of the uncoupled models. The heat flux consists of solar radiation, thermal radiation, latent and sensible heat fluxes. The fresh-water flux is given by the balance of precipitation, evaporation, and river run-off into the ocean. The SST (in our case the temperature of the uppermost ocean layer) and the sea-ice thickness are taken as boundary conditions for the atmospheric model. Both fields are calculated in the oceanic model component. As with the atmosphere-ocean fluxes, the SST is flux corrected.

In the synchronous mode the atmospheric model is integrated over one day (i.e. 36 time steps). The averaged atmosphere-ocean fluxes of heat and fresh water, which are calculated during this model day, are passed over to the oceanic model in order to perform a time step for the uppermost ocean layer over the same time period of one day. The resulting SST and sea-ice distributions of the ocean integration are taken as boundary conditions for the following simulation of the atmosphere over the next time period of one day. Every 30 days a time step for all ocean layers is performed. In addition to the heat and fresh-water fluxes, the wind stress is taken as ocean forcing for this time step in order to simulate the dynamic processes.

\subsection{The periodically synchronous coupling}

When the periodically synchronous coupling method is applied, periods with synchronous coupling alternate with periods during which only the ocean model is integrated. Due to the reduced

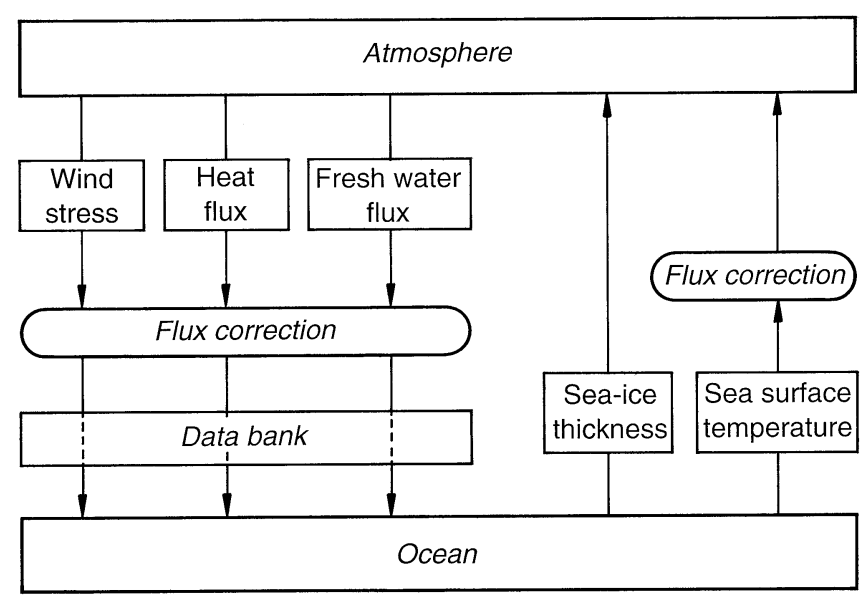

Fig. 1 Coupling of the atmosphere model ECHAM3 with the ocean model LSG 
simulation periods of the atmosphere, a periodically synchronously coupled model consumes less computer resources than the corresponding synchronously coupled model version. The technique which has been applied in the present study was developed by means of a non-linear zero-dimensional energy-balance model. Since a detailed description of the technique is given in SV and VS, we here concentrate on some special aspects and on topics which have to be different due to the different type of models. The terminology used in this article is the same as in VS.

The coupling procedure is divided into three main steps:

Step 1 During the last 12 months of a synchronously coupled period Storing the daily values of the heat and fresh-water fluxes and the monthly values of the wind stress components $f_{\text {syn }}$, which are passed over from the atmospheric model to force the oceanic model, in the data bank (Fig. 1).

Step 2 At the end of a synchronously coupled period Calculating forcing $f_{\text {oce }}$ for the following ocean-only period by means of $f_{s y n}$ and annual mean fluxes (see later).

Step 3 During the ocean-only period

Forcing ocean with the same annual cycle $f_{\text {oce }}$ for each year of the ocean-only period.

After finishing step 3 the cycle starts again.

In order to determine the forcing for the ocean-only periods (step 2) the annual mean fluxes of the just-finished synchronously coupled period $\mathscr{F}_{\text {syn }}$ and the annual mean fluxes of the last ocean-only period $\mathscr{F}_{\text {oce }(\text { old })}$ are used. A new annual mean $\mathscr{F}_{\text {oce }}$ is calculated:

$\mathscr{F}_{\text {oce }}=\frac{g \mathscr{F}_{\text {oce }(\text { old })}+\mathscr{F}_{\text {syn }}}{g+1}$

with the weight $g \geq 0$. This weighting procedure of the annual means reduces the interannual variability of the atmosphere-ocean fluxes. We chose $g=2$ for the following experiments, since this value proved to be successful in the case of the energy-balance model (see VS). In the study performed with the energy-balance model, we focused on a satisfactory reproducibility of the mean state and the transient behaviour. The daily and monthly values $f_{\text {oce }}$ of the annual cycle for the ocean-only periods are calculated from the annual means $\mathscr{F}_{\text {oce }}, \mathscr{F}_{\text {syn }}$, and from the values $f_{\text {syn }}$ of the last 12 months of the just-finished synchronously coupled period (step 1):

$f_{\text {oce }}=f_{\text {syn }}-\mathscr{F}_{\text {syn }}+\mathscr{F}_{\text {oce }}$.

The time mean of $f_{\text {syn }}$ is shifted from $\mathscr{F}_{\text {syn }}$ to the weighted annual mean $\mathscr{F}_{\text {oce }}$. This procedure saves the intraseasonal variability and damps the interannual variations. The annual means $\mathscr{F}$ and annual cycles $f$ are available for each atmosphere-ocean flux and for each oceanic grid point.

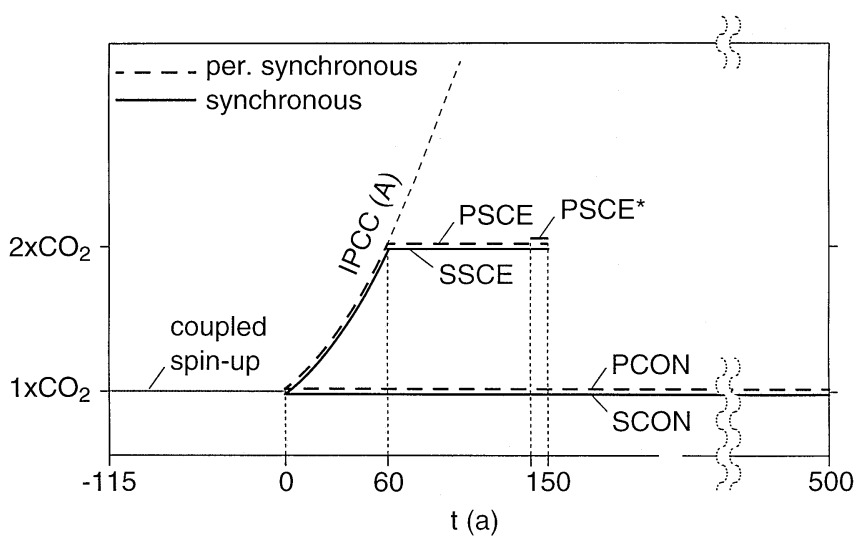

Fig. 2 Design of the numerical experiments
The synchronously coupled and ocean-only periods of the presented periodically synchronous experiments last $(3+12)$ months and 48 months, respectively. This choice of the period lengths, which was motivated by the tests performed with the energy balance model, leads to a considerable reduction of the computer time relative to the purely synchronously coupled model. The first three months of each synchronously coupled period are not stored in the data bank to avoid a possible shock at the beginning of the synchronously coupled period, due to a change of the ocean state during the previous ocean-only period, affecting the forcing stored in the data bank. After each ocean-only period the atmospheric model restarts from the state reached at the end of the previous synchronously coupled period.

As the atmospheric component ECHAM3 consumes more than $90 \%$ of the computer time of the synchronously coupled model, approximately $70 \%$ of the computer time is saved in the periodically synchronously coupled model version (see also Fig. 3 in VS).

\section{The experiments}

The spin-up procedure of the uncoupled models is based upon the experience obtained during the development of the AOGCMs ECHAM1/LSG (Cubasch et al. 1992) and ECHAM2/OPYC (Lunkeit et al. 1996). Before coupling, both models were spun-up with boundary conditions taken from observed climatological data sets. The oceanic model was integrated over $27000 \mathrm{y}$ and the atmospheric component over $20 \mathrm{y}$ (for details see Voss 1996).

After the preparation of the uncoupled components, the synchronously coupled model was integrated over $115 \mathrm{y}$ starting from the state which was reached by the uncoupled models at the end of the spin-up procedure. During the last ten years of this coupled integration the data bank was filled up, since the annual mean atmosphere-ocean fluxes of the ocean-only periods partly consist of annual-mean fluxes of previously calculated synchronously coupled periods (see Sect. 2.4). All runs investigated in this study were started from the state of the coupled model reached after the 115-y integration.

In order to compare both coupling techniques a set of four simulations has been performed (Fig. 2). The synchronously and periodically synchronously coupled model versions were integrated over $500 \mathrm{y}$ with the unchanged present-day $\mathrm{CO}_{2}$ concentration (denoted as SCON - Synchronously coupled experiment with CONstant $\mathrm{CO}_{2}$ concentration and PCON - Periodically synchronously coupled experiment with $\mathrm{CON}$ stant $\mathrm{CO}_{2}$ concentration). In addition, both model versions were integrated over $150 \mathrm{y}$ applying a scenario with increasing $\mathrm{CO}_{2}$ concentration. The $\mathrm{CO}_{2}$ concentration follows the IPCC "Business as Usual" scenario A (Houghton et al. 1990) until the $\mathrm{CO}_{2}$ doubling is reached after $60 \mathrm{y}$. The $\mathrm{CO}_{2}$ concentration remains unchanged for the following years (experiments SSCE Synchronously coupled experiment with the $\mathrm{CO}_{2}$ concentration according to the SCEnario described already and PSCE - Periodically synchronously coupled experiment with the $\mathrm{CO}_{2}$ concentration according to 
the SCEnario). A similar evolution of the $\mathrm{CO}_{2}$ concentration was used by Manabe and Stouffer (1994) for a 500-y simulation of a synchronously coupled AOGCM.

We particularly focus the investigation of the climate-change patterns due to the increased $\mathrm{CO}_{2}$ concentration on the years 141-150. A direct comparison of the atmospheric data sets of this 10 -y period is not meaningful, since only two full annual cycles of the atmosphere are computed in the periodically synchronously coupled run PSCE. Hence, an additional synchronously coupled integration PSCE* has been performed which was started from the state reached by the experiment PSCE after year 141-150. The experiment PSCE* only simulates the period 141-150.

The main objective for our study is the evaluation of the periodically synchronous coupling scheme by a comparison to the synchronous coupling scheme:

1. In Sect. 4 the reproducibility of a climate state described by the mean state and the variability on timescales ranging from years to decades is investigated.

2. In Sect. 5 the transient behaviour and the climatechange pattern of both model versions due to a transient $\mathrm{CO}_{2}$ increase are compared.

\section{Reproduction of a mean state}

\subsection{Time evolution}

Both, the synchronously and the periodically synchronously coupled experiments, SCON and PCON, have been integrated over a period of $500 \mathrm{y}$ with constant present-day $\mathrm{CO}_{2}$ concentration. The time evolution of global-mean values is similar for both runs. Figure 3 displays horizontal averages of the temperature. Shown are the deviations from the mean of the first $10 \mathrm{y}$ of the experiment SCON. The dots in Fig. 3a indicate the averages of the near-surface air temperature for the last 12 months of the synchronously coupled periods of the experiment PCON and the solid curve shows the evolution of the annual-mean temperatures of the run SCON. In addition to fluctuations on different time scales, the near-surface air temperature exhibits a trend. The temperature increases approximately $0.75 \mathrm{~K}$ during the simulated period of $500 \mathrm{y}$. The strongest increase $(0.5 \mathrm{~K})$ occurs between the years 50 and 150 . Due to the strong coupling of the atmospheric boundary layer to the upper ocean, the temperature of the uppermost ocean layer, which serves as sea surface temperature in the coupled model, exhibits a similar time evolution with a warming of $0.6 \mathrm{~K}$ after $500 \mathrm{y}$ (Fig. $3 \mathrm{~b})$. The trend in the deep ocean is more uniform during the simulation. At $2000 \mathrm{~m}$ depth, for instance, the temperature increases $0.09 \mathrm{~K}$ per century (Fig. 3c). Whereas the trend in the near-surface air temperature and SST seem to be due to an imperfection of the determination of the flux correction terms, the trend in
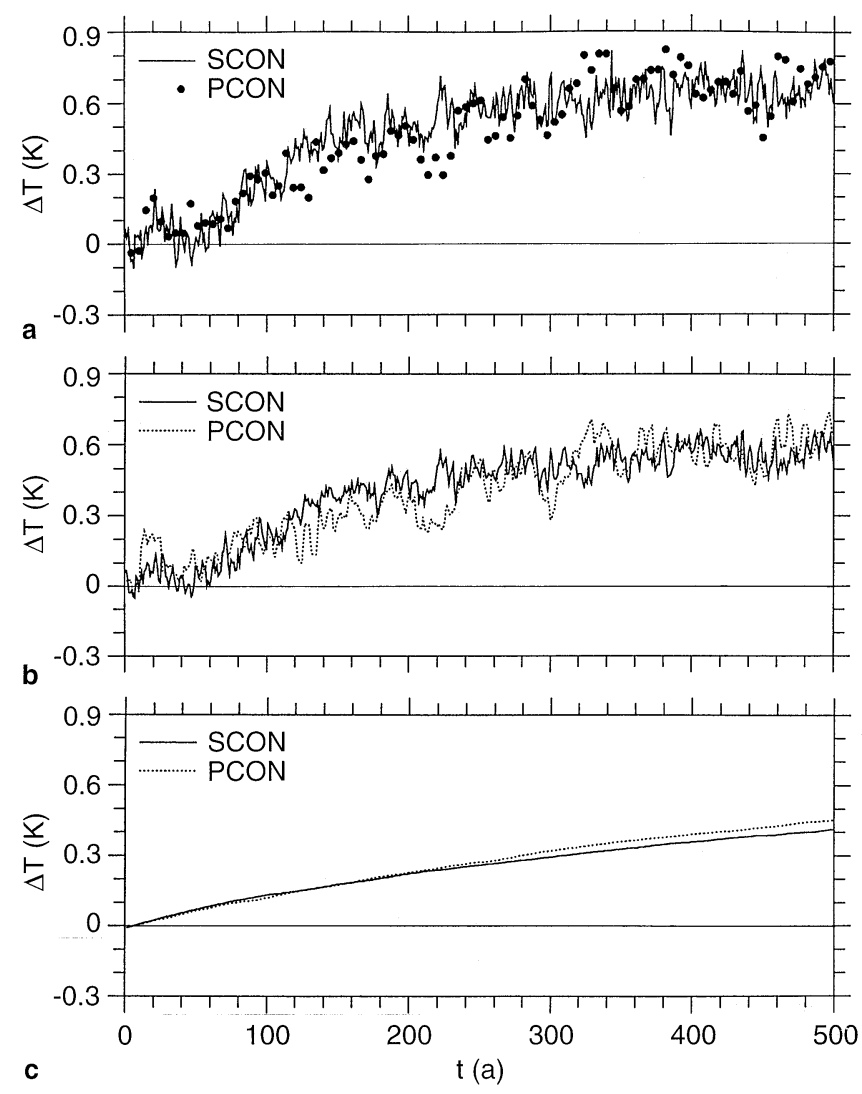

Fig. 3a-c Time evolution of the anomalies of the a global-mean near-surface air temperature, $\mathbf{b}$ the global-mean ocean temperatures for the uppermost ocean layer $(25 \mathrm{~m})$ and $\mathbf{c}$ for the model layer centred in $2000 \mathrm{~m}$ depth. The respective means of the first decade of the experiment SCON are subtracted. The dots in a indicate the means of the last 12 months of the synchronously coupled periods of the experiment PCON

the deep ocean may be caused by the spin-up procedure. Both problems require further investigations.

In order to locate the regions of climate drift, the mean distributions of the near-surface air temperature for two different periods of the synchronously coupled experiment SCON are compared in Fig. 4. The average of the first $50 \mathrm{y}$ (Fig. 4, upper-left panel) represents the state of the initial period without a distinct trend, whereas the average of the years 451-500 represents the state at the end of the simulation. The differences between both distributions (Fig. 4, bottom-left panel) indicate a considerable warming in the southern high latitudes. The largest differences with values of more than $10 \mathrm{~K}$ are located in the vicinity of the Antarctic continent. In other regions the deviations are much smaller. Differences below $0.5 \mathrm{~K}$ are typical for the tropics and mid latitudes of the Northern Hemisphere.

A reduction of the Antarctic sea ice is the main reason for the strong warming over the Southern Ocean. The annual maximum of the sea-ice extent decreases from $7 \cdot 10^{6} \mathrm{~km}^{2}$ to $2 \cdot 10^{6} \mathrm{~km}^{2}$ in the period from year 50 to year 150. In connection with the reduction of the icecovered area, the heat release of the ocean increases 
$\operatorname{SCON}(1-50)$

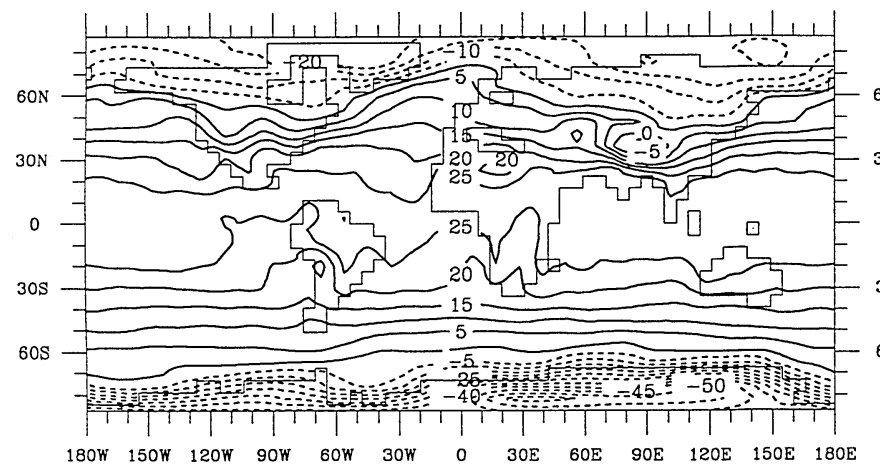

SCON (451-500) - SCON (1-50)

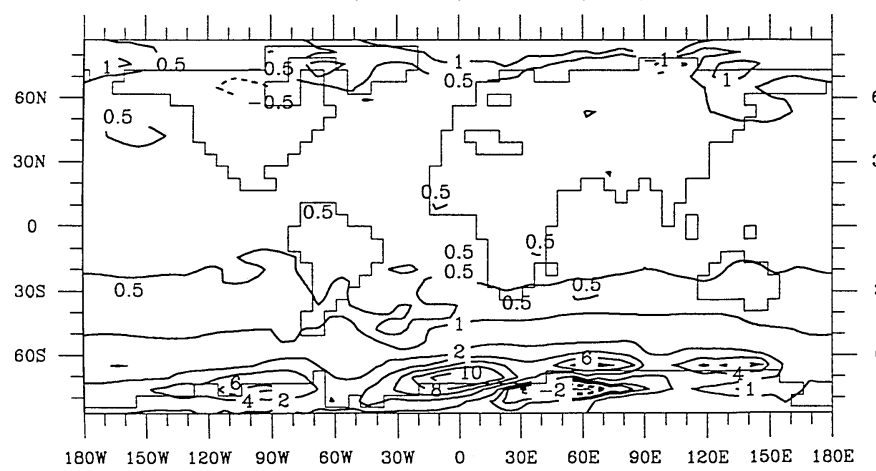

Fig. 4 Horizontal distributions of the mean near-surface air temperatures $\left({ }^{\circ} \mathrm{C}\right.$ ) for the first $50 \mathrm{y}$ of the experiment SCON (left-upper panel), the difference (K) between the interval 451-500 and the first 50 y (left-bottom panel), the differences between the last $50 \mathrm{y}$ of the experiments PCON and SCON (right-upper panel), and the

in this region. As a consequence the near-surface air temperature rises. In the following years the sea-ice distribution of the Southern Hemisphere remains quasi-stationary and the rise of the globally averaged near-surface air temperature is considerably reduced.

As can be seen from the differences between the mean distributions of the years 451-500 (Fig. 4, upper-right panel) both model versions, SCON and PCON, show nearly the same systematic bias. The averages of the PCON run consist of the near-surface air temperatures of the last 12 months of the synchronously coupled periods. The differences of the horizontal distributions are small compared to the variability of the experiment SCON. As a measure for the model variability the standard deviations of the annual mean values of the years 451-500 are used (Fig. 4, bottom-right panel). The comparison between differences and standard deviations shows that the regions with larger deviations are also characterized by high variability, with the exception of a small region at the sea-ice margin in the northern part of the North Atlantic.

\subsection{Mean state of the atmosphere}

As can be seen from the near-surface air temperature in Fig. 4, the synchronously and periodically syn-

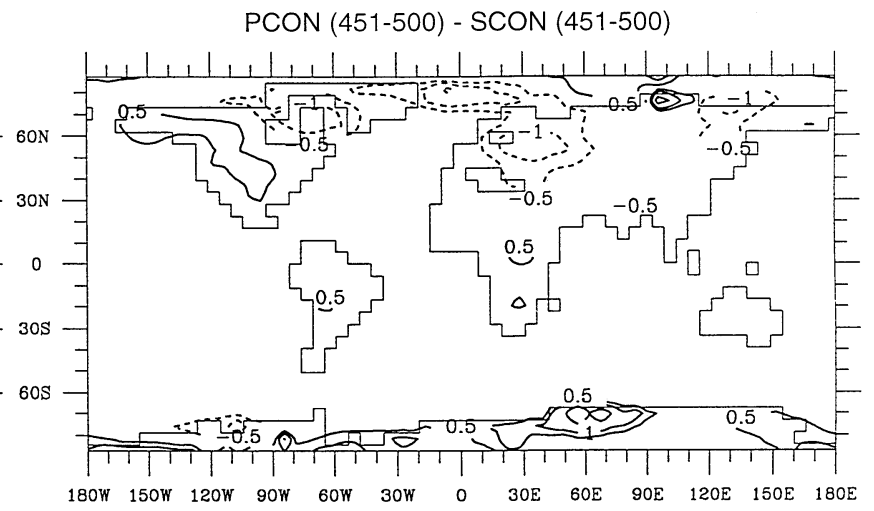

$\sigma(\operatorname{SCON}(451-500))$

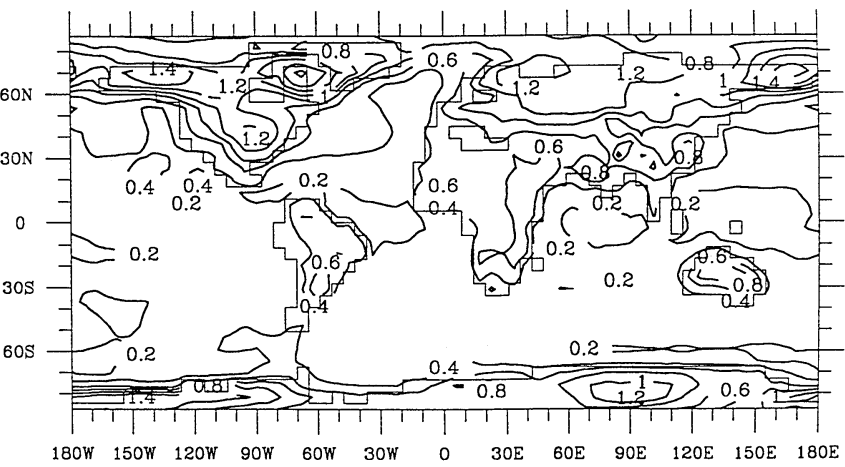

standard deviations of the annual mean values of the experiment SCON (right-bottom panel). Contours for the differences: \pm 0.5 , $\pm 1, \pm 2, \pm 4, \pm 6, \pm 8, \pm 10, \pm 12 \mathrm{~K}$. Contour interval for standard deviations: $0.2 \mathrm{~K}$

chronously coupled model versions produce differences between each other in the range of the interannual variability of the synchronously coupled model. In order to analyse the atmospheric states in more detail, the model data of the years 451-500 have been examined for different seasons. In the following only two characteristic examples for the seasonal means of the months December, January, and February (DJF) are presented. Other seasons exhibit similar characteristics. The last 10 periods of synchronous coupling in the experiment PCON are compared to the 50-y continuous data set of the run SCON. In order to estimate the importance of the differences between both experiments, a measure of the variability for the experiment SCON was chosen. For this reason the standard deviations of the seasonal means for the period 451-500 were computed. The standard deviations of the seasonal means for this 50-year period are higher than the respective values computed from seasonal means averaged over 10 or 50 years, which would be more appropriate for this comparison. Due to the model drift and a small sample size, the standard deviations of the decadal or multi-decadal means show larger uncertainties. Therefore, the standard deviations of the seasonal means are used only as a qualitative measure of the variability. In order to compare the model results with the observed climate state, the ECMWF analysis of the years 1980-1994 are employed. 

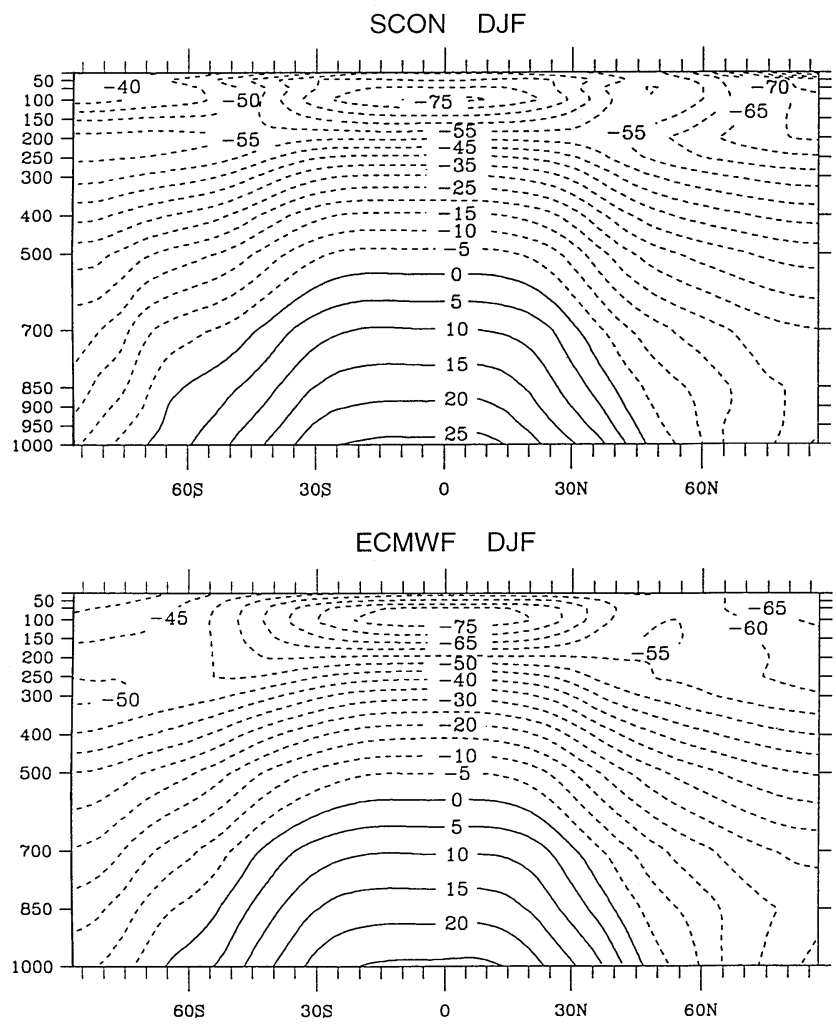

Fig. 5 Latitude-altitude distributions of the zonal-mean temperatures $\left({ }^{\circ} \mathrm{C}\right)$ of DJF for the period $451-500$ of the experiment SCON (left-upper panel), the analysis of the ECWMF (left-bottom panel), the differences $(\mathrm{K})$ between the period $451-500$ of the experiments

In the troposphere the zonally averaged atmospheric temperatures (Fig. 5) are reasonably well simulated. Compared to the ECMWF analysis the temperatures of the polar upper troposphere and lower stratosphere are too cold. The tropical upper troposphere of the model exhibits a warm bias. In the lower and middle troposphere the zonal-mean temperature is well reproduced. The comparison of both model runs shows temperature differences up to $1 \mathrm{~K}$. However, only in the polar stratosphere of the Southern Hemisphere the values are the same order of magnitude as the standard deviations of the synchronously coupled run SCON.

The geopotential height field at $500 \mathrm{hPa}$ (Fig. 6) of the Northern Hemisphere is realistically simulated by the model. The most striking difference to the observations is the overestimation of the height of the Atlantic trough. The differences between the model runs show in the run PCON a slight westward shift of the trough axes. Nevertheless, the deviations of the geopotential height field are smaller than the standard deviations of the experiment SCON.

The examples of the vertical temperature structure and the general circulation of the atmosphere show good agreement between both model runs. That is, the discrepancies which occur between both
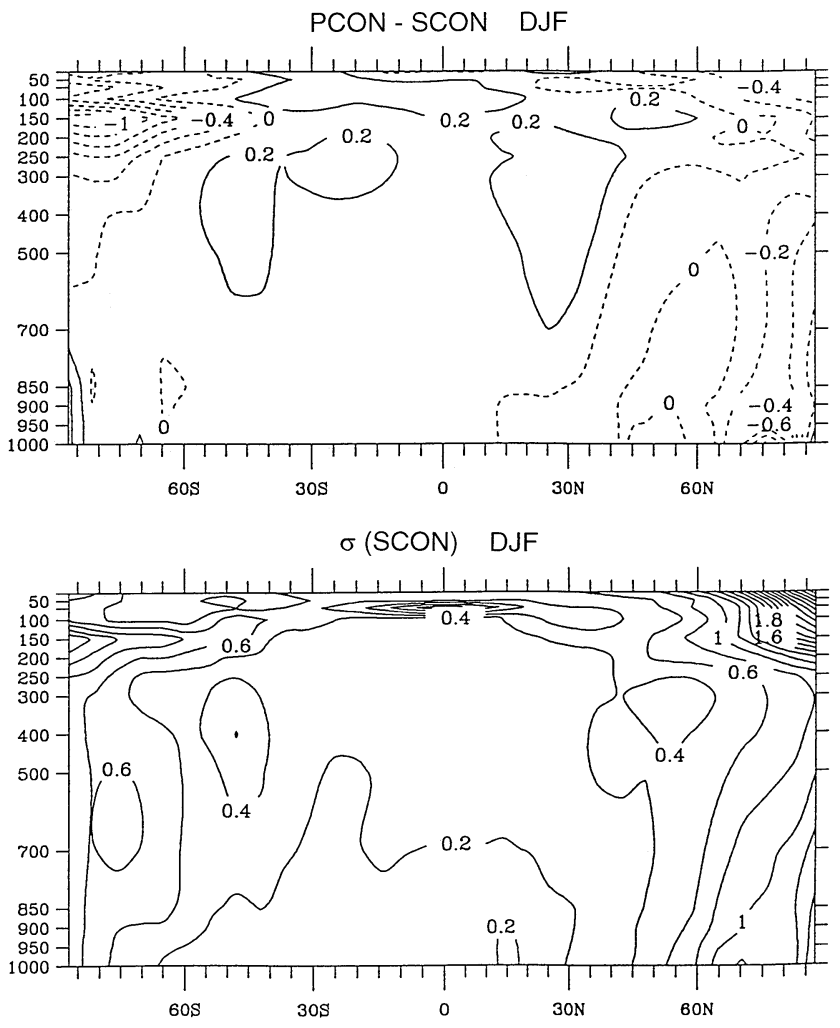

PCON and SCON (right-upper panel), and the standard deviations of the seasonal mean values of the experiment SCON (right-bottom panel). Contour intervals are $5 \mathrm{~K}$ for mean distributions and $0.2 \mathrm{~K}$ for differences and standard deviations

runs are smaller than, or of the same order of magnitude as, the interseasonal standard deviations of the synchronously coupled run SCON. The systematic model errors of both coupled model versions are close to the discrepancies of the uncoupled atmospheric model ECHAM3 with the same horizontal resolution of T21 (Roeckner et al. 1992). These systematic errors of the uncoupled ECHAM3 are larger than the discrepancies between both coupled model versions. The presented results are also transferable to other seasons and other important climate variables (e.g. wind or precipitation). In other words, the atmospheric mean state is satisfactorily reproduced by the periodically synchronously coupled model compared to the uncoupled AGCM and the synchronously coupled AOGCM.

\subsection{Mean state of the ocean}

The averages of the zonal-mean oceanic temperature for the period 451-500 are chosen as an example for the mean states of the ocean in the experiments SCON and PCON. The mean states are compared to the observational data from Levitus (1982) which have been adapted to a $5^{\circ}$ E-type grid (Fig. 7). The structure is well 
Fig. 6 Distributions of the geopotential height field at 500 hPa (gpdam) of DJF for the period 451-500 of the experiment SCON (left-upper panel), the analysis of the ECWMF (left-bottom panel), the differences between the period 451-500 of the experiments PCON and SCON (right-upper panel), and the standard deviations of the seasonal mean values of the experiment SCON (right-bottom panel). Contour interval are 8 gpdam for mean distributions and 1 gpdam for differences and standard deviations
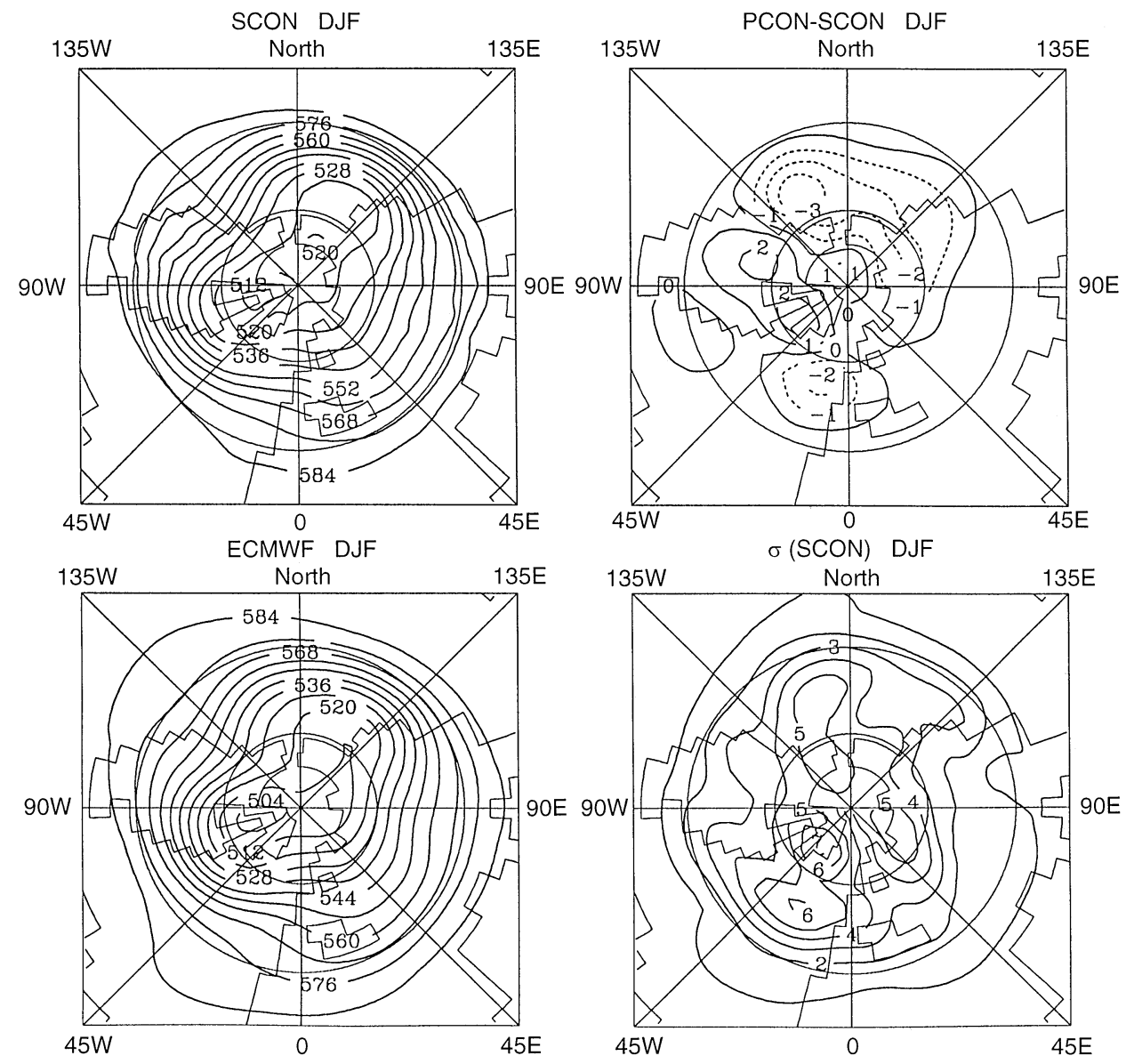

reproduced, but the magnitude shows some remarkable discrepancies. In the upper layers of the tropical ocean the temperature is approximately $2 \mathrm{~K}$ too cold. In the deep ocean and in the entire Southern Ocean the temperatures are overestimated by both model versions. The differences between the distributions of the experiments SCON and PCON are much smaller than the model bias.

As an example for the circulation of the ocean, the meridional overturning circulation of the Atlantic is shown in Fig. 8 for both experiments. The circulation of the Atlantic, especially the deep-water formation of the North Atlantic, is an important part of the conveyor belt circulation (e.g. Gordon 1986; Broecker 1991). The model results show a strong inflow from the Southern Ocean in the upper layers of the Atlantic. In the North Atlantic the water sinks and flows in deeper layers back into the Southern Ocean. An additional inflow from the south into the Atlantic, the Antarctic bottomwater, can be observed at large depths. The simulated meridional circulation of both model versions show the same characteristics as the uncoupled standard version of the LSG (Maier-Reimer et al. 1993). Both the outflow from the Atlantic into the Southern Ocean (about $18 \mathrm{~Sv}$ ) and the overturning in the North Atlantic (maximum of
$28 \mathrm{~Sv}$ ) are stronger than estimated from observations (e.g. Gordon 1986; Schmitz 1995). Small differences between both model versions may be caused by interdecadal variability of the North Atlantic thermohaline circulation, with a period length of approximately $35 \mathrm{y}$ (Timmermann et al. 1998).

\subsection{The variability}

In addition to the mean state, which has been described in the two previous subsections, the variability characterizes a climate state. In this subsection we examine the variability from interannual to interdecadal time scales. The investigations are based on the time series of the annual-mean values of the experiments SCON and PCON.

In tests performed with a simple zero-dimensional energy-balance model (see VS) the periodically synchronously coupled integrations were characterized by a higher standard deviation of the time series than the corresponding synchronously coupled integrations. The overestimation of the fluctuations depends on the value of the weight $g$ (see Eq. 1) and on the length of the 

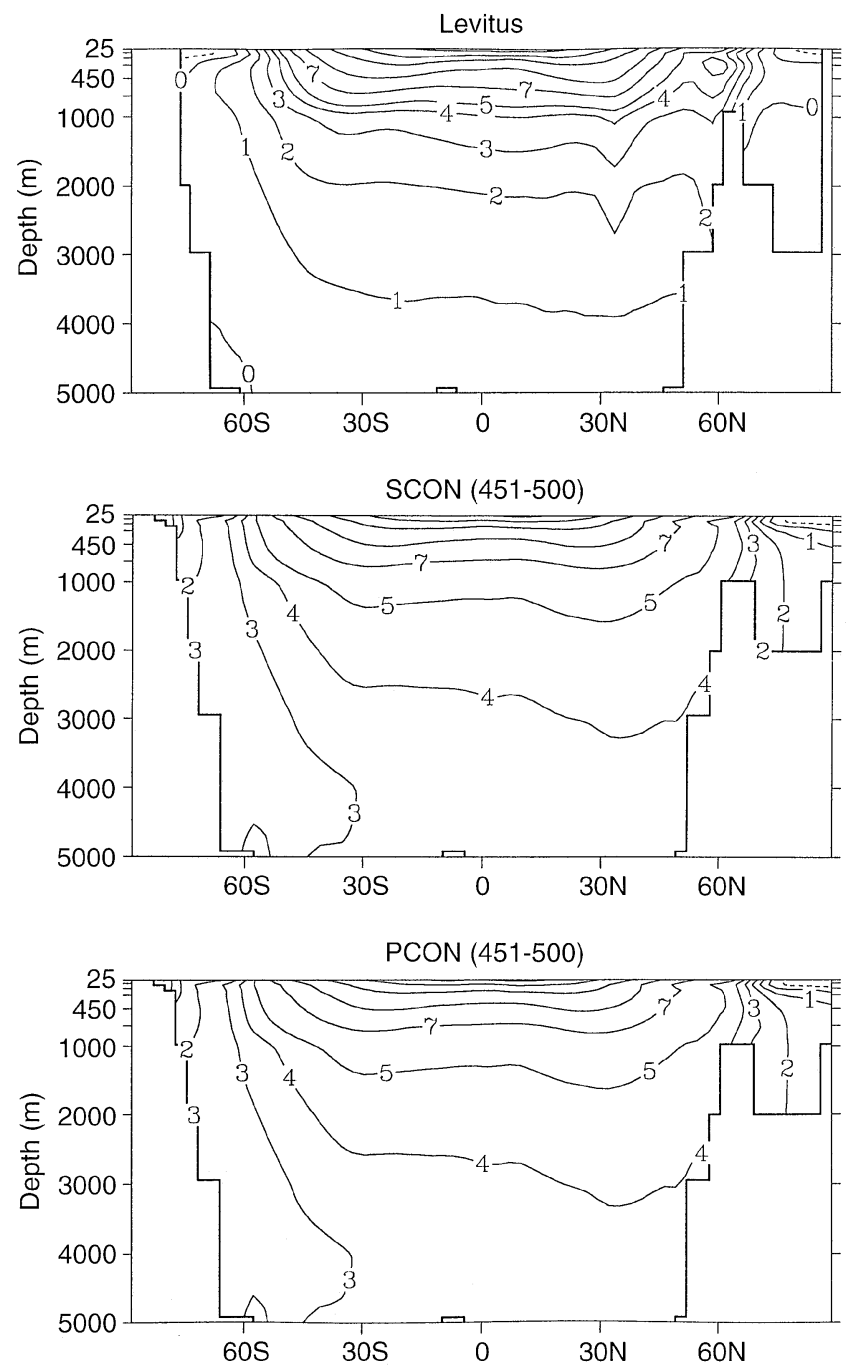

Fig. 7 Zonal-mean ocean temperature $\left({ }^{\circ} \mathrm{C}\right.$ ) for observations (upper panel; Levitus 1982) and the mean distributions of the period 451-500 for the experiments SCON (middle panel) and PCON (bottom panel). Contours for $-1,0,1,2,3,4,5,7,10,15,20,25^{\circ} \mathrm{C}$

ocean-only periods. With increasing weight $g$ the damping of the variability increases and the standard deviations converge to the corresponding value of the synchronously coupled integration. A large weight, on the other hand, causes a time-lag of the response to perturbations of the coupled model. The longer the ocean-only periods the more computer resources are saved. On the other hand, with increasing length of the ocean-only periods, the overestimation of the variability also increases. This is mainly due to the missing thermal damping feedback of the atmosphere during the ocean-only periods, which could cause a small drift of the ocean during these periods.

The period lengths and the weighting factor $g$ of the present experiments were chosen according to the results achieved with the simple model of VS. The weight $g=2$ and the period lengths reflect a point in the
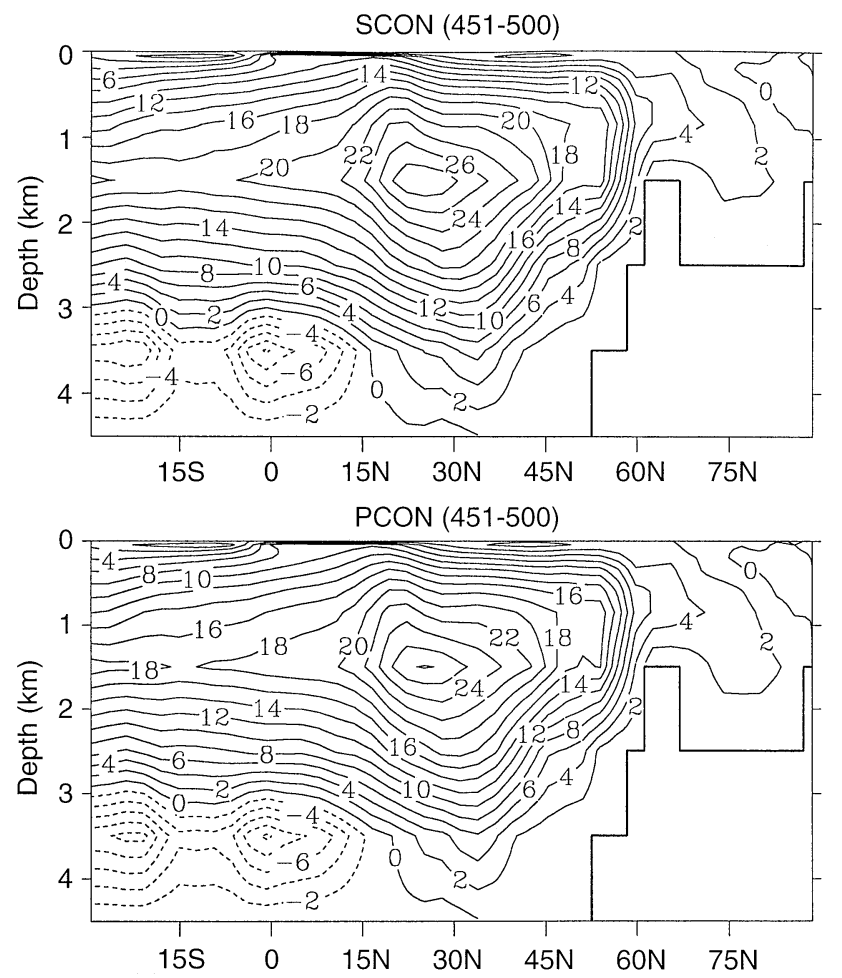

Fig. 8 Meridional stream function of the Atlantic for the experiments SCON (upper panel) and PCON (bottom panel). The means for the period 451-500 are displayed. Positive values indicate a clockwise rotation. Contour interval: $2 \mathrm{~Sv}$

parameter space where the simple model produces suitable results concerning the mean state and the transient behaviour. Since the experiments of the periodically synchronously coupled AOGCM are still expensive, our experiments have been restricted to this single choice of the parameters.

The overestimated standard deviations of the periodically synchronously coupled model can also be observed in the case of the atmosphere-ocean general circulation model. In order to compare the amplitude of the fluctuations, the annual-mean values of oceanic temperature and salinity for the period 451-500 have been chosen. In Table 1 the horizontally averaged standard deviations of the run SCON, $\sigma_{S C O N}$, are listed for each ocean layer. The values of both variables decrease more than one order of magnitude from upper to deep ocean. The ratios of the standard deviations between the periodically synchronously and the synchronously coupled runs, $\sigma_{P C O N} / \sigma_{S C O N}$, cover a range from 0.93 to 1.45. Except for the salinity of the uppermost ocean layer, all values are greater than one. That is, in agreement with the results of the simple model, the periodically synchronously coupled model produces on average a higher standard deviation than the synchronously coupled AOGCM does.

The spatial distribution of the ratio $\sigma_{P C O N} / \sigma_{S C O N}$ for the temperature of the uppermost ocean layer $(25 \mathrm{~m})$ is displayed in Fig. 9. The values for the permanently 
Table 1 Global averages of the standard deviations $\sigma$ for the experiment $\mathrm{SCON}$ and the corresponding ratios of the standard deviations between the experiments PCON and SCON. The computation is based on annual means for the period $451-500$

\begin{tabular}{cllll}
\hline & \multicolumn{3}{l}{ Semperature } & \multicolumn{3}{l}{} \\
\cline { 2 - 5 } Depth & $\sigma_{\text {SCON }}(\mathrm{K})$ & $\sigma_{\text {PCON }} / \sigma_{\text {SCON }}$ & $\sigma_{\text {SCON }}\left(10^{-3} \%\right.$ oo & $\sigma_{\text {PCON }} / \sigma_{\text {SCON }}$ \\
\hline $25 \mathrm{~m}$ & 0.37 & 1.27 & 7.34 & 0.93 \\
$75 \mathrm{~m}$ & 0.25 & 1.09 & 4.49 & 1.13 \\
$150 \mathrm{~m}$ & 0.18 & 1.03 & 2.79 & 1.20 \\
$250 \mathrm{~m}$ & 0.13 & 1.08 & 1.56 & 1.31 \\
$450 \mathrm{~m}$ & 0.07 & 1.08 & 0.78 & 1.45 \\
$700 \mathrm{~m}$ & 0.04 & 1.02 & 0.41 & 1.41 \\
$1000 \mathrm{~m}$ & 0.02 & 1.11 & 0.19 & 1.12 \\
$2000 \mathrm{~m}$ & 0.01 & 1.25 & 0.14 & 1.13 \\
$3000 \mathrm{~m}$ & 0.01 & 1.23 & 0.13 & 1.14 \\
$4000 \mathrm{~m}$ & 0.01 & 1.21 & 0.14 & 1.06 \\
$5000 \mathrm{~m}$ & 0.01 & 1.13 & 0.12 & \\
\hline
\end{tabular}

Fig. 9 Ratio of the standard deviations (PCON:SCON) of the annual-mean temperatures of the uppermost ocean layer for the period $451-500$

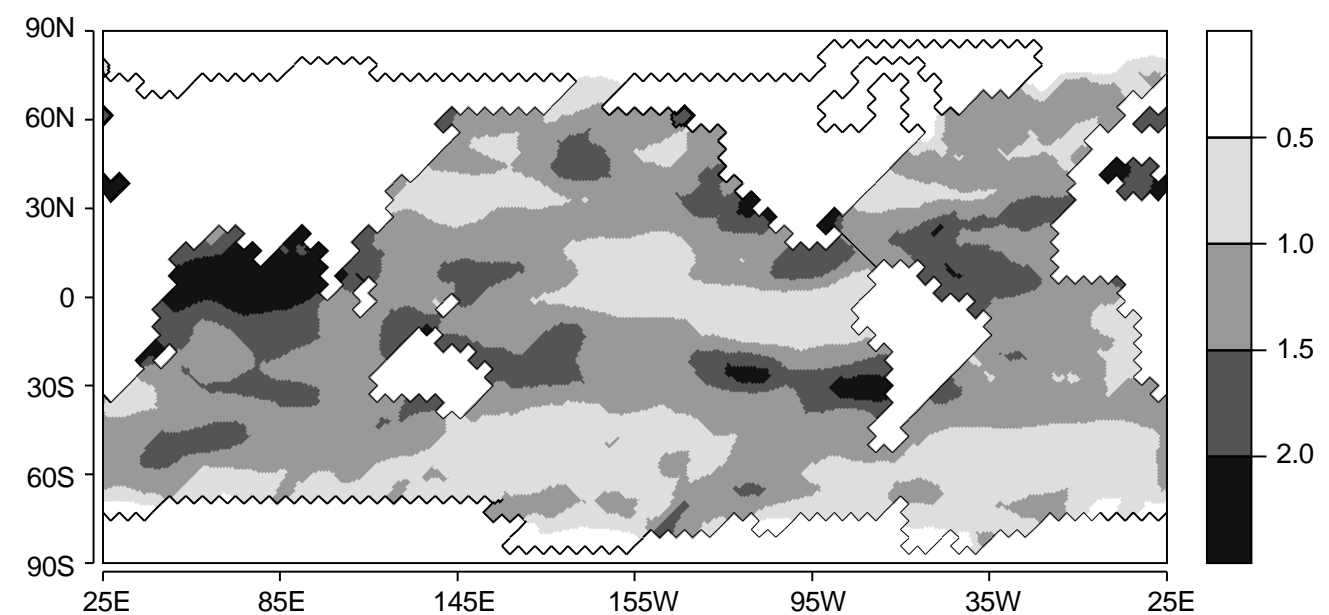

ice-covered grid points are set to zero, as the temperature for these points is assumed to be the constant freezing-point temperature. In large regions of the ocean, especially in the Southern Ocean and the tropical Pacific, the ratio is below 1, i.e., the standard deviation of the periodically synchronously coupled experiment PCON is smaller than in the reference run SCON. Nevertheless, regions with a larger standard deviation predominate. In the northern part of the Indian Ocean and at the Chilean coast the ratio exceeds 2 . The pattern shown for the period $451-500$ is not a stable feature. The analysis of different 50-y periods shows the regions with ratios below and above one change with time. Only the general tendencies of the globally averaged values with a higher standard deviation in the periodically synchronously coupled integration appears to be a stable feature.

The different characteristics of the variability also show up in the spectral properties. In order to investigate the variability of both coupled model versions, an analysis of the uppermost ocean layer temperature by means of empirical orthogonal functions (EOFs) has been performed. In order to compare the time series of the principal components (PCs), the fields of the PCON run have been projected onto the EOFs of the SCON run. The projection is justified by a large similarity of the leading EOFs, when computed separately for both experiments. The pattern correlation for the first and second EOFs, which are analyzed in the following, are 0.95 and 0.75 , respectively.

The first EOF of the experiment SCON (Fig. 10, upper panel) explains more than $41 \%$ of the variance of SCON and $31 \%$ of PCON. This pattern reflects mainly the temperature change which is caused by the model drift (see Fig. 3). In accordance, the corresponding time series of the PCs (Fig. 11a) describe a similar evolution of the globally averaged temperature of the uppermost ocean layer (Fig. 3b). The pattern of the second EOF, with maxima in the North Atlantic and North Pacific, explains $6 \%$ of the variance of SCON and $3 \%$ of PCON (Fig. 10, bottom panel). The time series of the PCs of this EOF show fluctuations on different time scales without a significant trend (Fig. 11b). The power spectra of these time series (Fig. 11c) illustrate an underestimation of the short-term variability and an overestimation of the long-term variability in the experiment PCON. This feature is also common to the PCs of the following EOFs. 

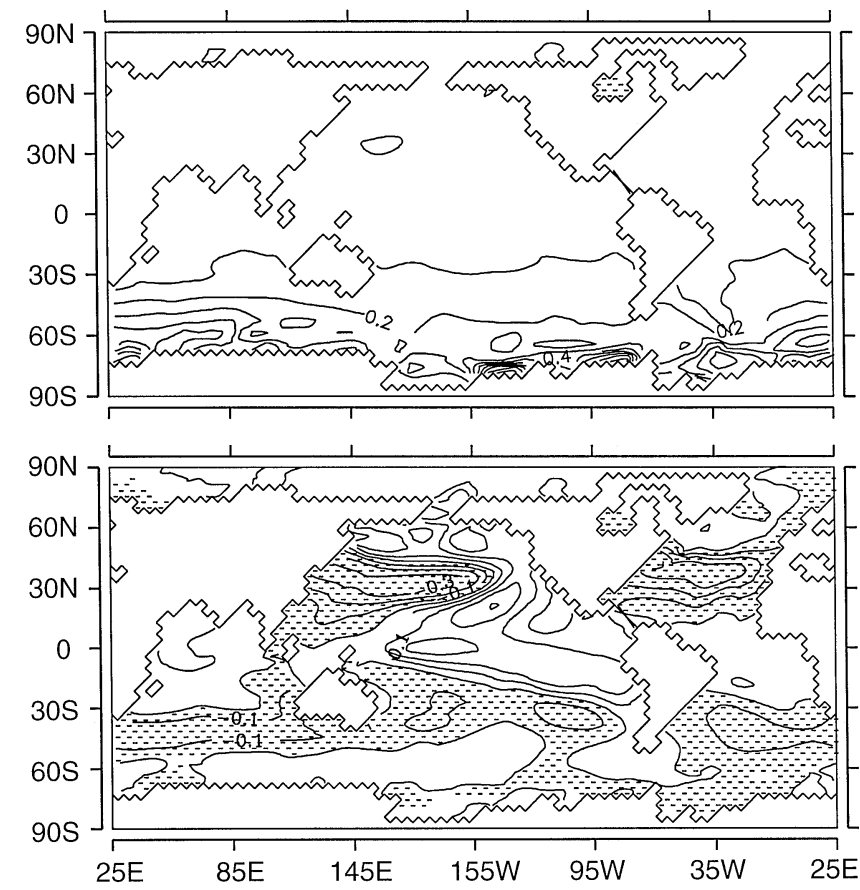

Fig. 10 Pattern of the first (upper panel) and the second EOF (bottom panel) of the annual mean temperatures of the uppermost ocean layer for the experiment SCON. Contour interval: 0.1

The different spectral properties of the oceanic time series are caused by the forcing during the ocean-only periods of the periodically synchronously coupled run. A time series with white-noise characteristics changes to an almost red-noise time series due to the weighting procedure of the annual means (Eq. 1) and the unchanged annual-mean fluxes during the ocean-only periods. A minimum of the variance shows up at a period length of 63 months, which is the sum of the lengths of the ocean-only (48 months) and the synchronously coupled periods (15 months). A second minimum occurs at 31.5 months, which is half the mentioned period. The transition between the underestimation of the short-term variability to the overestimation of the longterm variability occurs at a period of about $35 \mathrm{y}$.

This consideration of the spectral properties shows good agreement with the atmosphere-ocean freshwater flux of the ECHAM3/LSG. The atmosphereocean heat flux, however, shows a slightly different behaviour. This is illustrated by time series of the North Atlantic area means (north of $30^{\circ} \mathrm{N}$ ). In both runs the heat flux is characterized by a high variability (Fig. 12a; negative values indicate a flux out of the ocean). The power spectra of these time series show the expected underestimation of shorter periods in the periodically synchronously coupled experiment PCON (Fig. 13a). The transition from an underestimation of the shorter periods to an overestimation of the longer periods is over a period of about $20 \mathrm{y}$. In contrast to the freshwater flux, the heat flux is influenced by a direct feed-
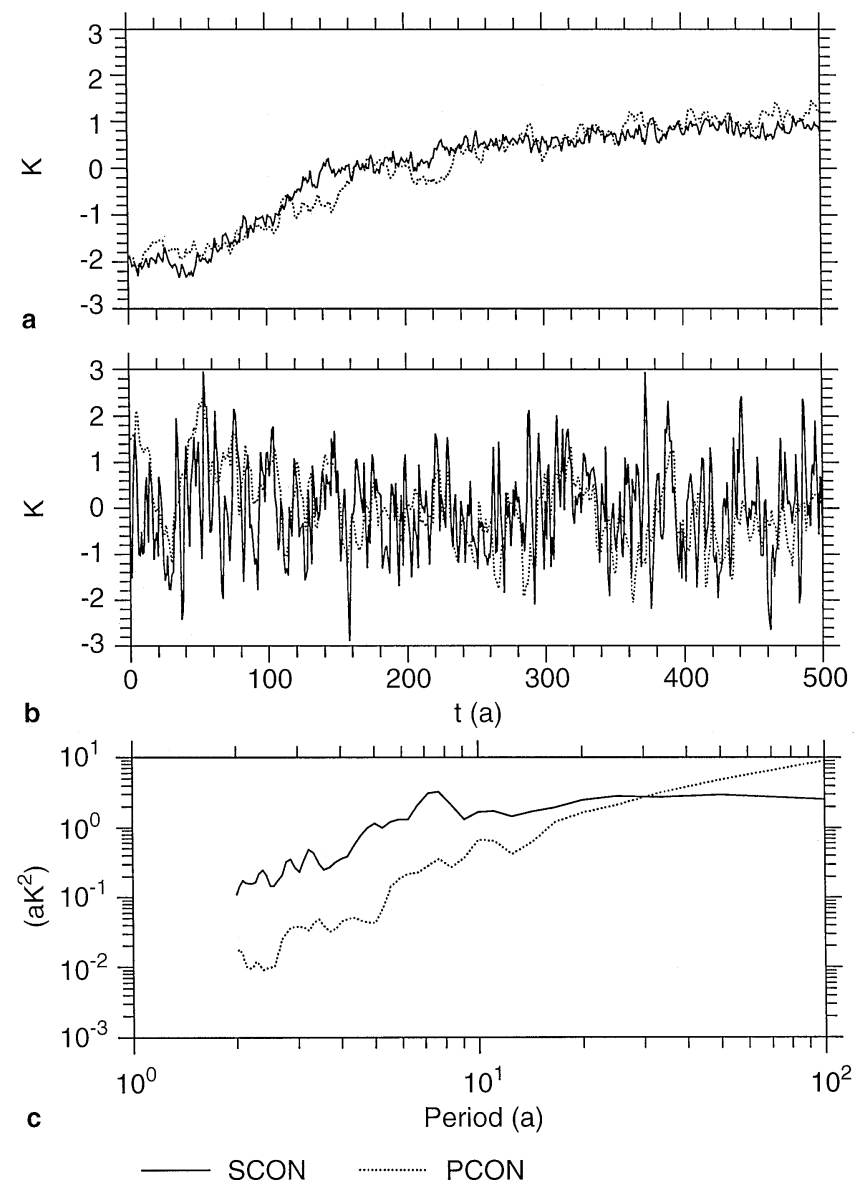

Fig. 11a-c Time series of the principal components of the a first and b second EOF of Fig. 10 and $\mathbf{c}$ the corresponding spectra for the time series of the second EOF. The spectra are calculated by means of the autocovariance function using a Hanning window with a maximum lag of $100 \mathrm{y}$

back of the ocean due to changes in SST. This feature may influence the spectral properties of the heat-flux forcing.

The corresponding time series of the uppermost ocean layer temperatures are displayed in Fig. 12b. The spectra of both time series (Fig. 13b) show for the SCON run an almost red-noise response to the ocean forcing, with its almost white-noise characteristics. This behaviour of the upper ocean was stated by Hasselmann (1976) by means of theoretical considerations. The range of the under- and overestimations of the variability shows good agreement with the changes in the spectral characteristics of the heat flux (Fig. 13a). A similar close connection exists between atmosphereocean fresh-water flux and salinity (not shown).

Beside the salinity and the oceanic temperature, which both mainly determine the oceanic stratification, the wind-stress field, with its changed spectral properties, influences the circulation of the ocean. Hence, we can also expect differences in the interannual variability of the convection. This should be especially the case in 

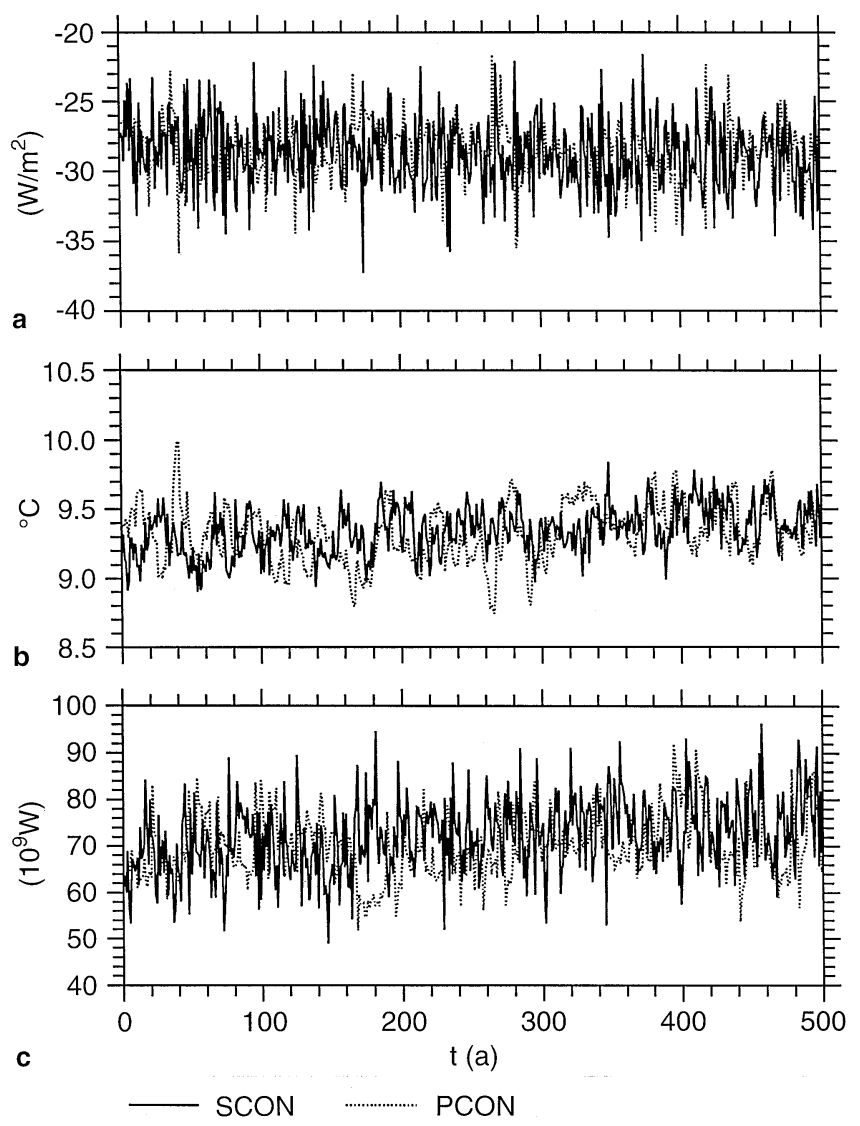

Fig. 12a-c Time evolution of a the heat flux, $\mathbf{b}$ the oceanic temperature of the uppermost ocean layer, and $\mathbf{c}$ the loss of potential energy by convection. The time series consist of annual-mean averages over the North Atlantic (north of $30^{\circ} \mathrm{N}$ )

the North Atlantic, since this is in the model, and in the real ocean, a region of strong convective activity. The time series of the loss of potential energy due to convection are characterized by high variability (Fig. 12c). This variable, which is a measure of the deep-water formation, also shows the characteristic changes of the spectral properties of the periodically synchronously coupled run (Fig. 13c).

Not only the upper ocean, with its strong coupling to the atmosphere-ocean fluxes, but also the deeper ocean layers, are affected by the different properties of the ocean forcing. One link between the upper and deep ocean is the convection, which is also characterized by the underestimated short-term variability, as already stated. Therefore, it is not surprising that, for example, the outflow of Atlantic deepwater into the Southern Ocean is also affected by the different variability of the ocean forcing in the periodically synchronously coupled model (not shown).

The underestimation of the variability for shorter periods is a common feature for different variables and different depths in the ocean model. Tests with the simple energy-balance model of VS show that the period lengths of the variability that are underestimated
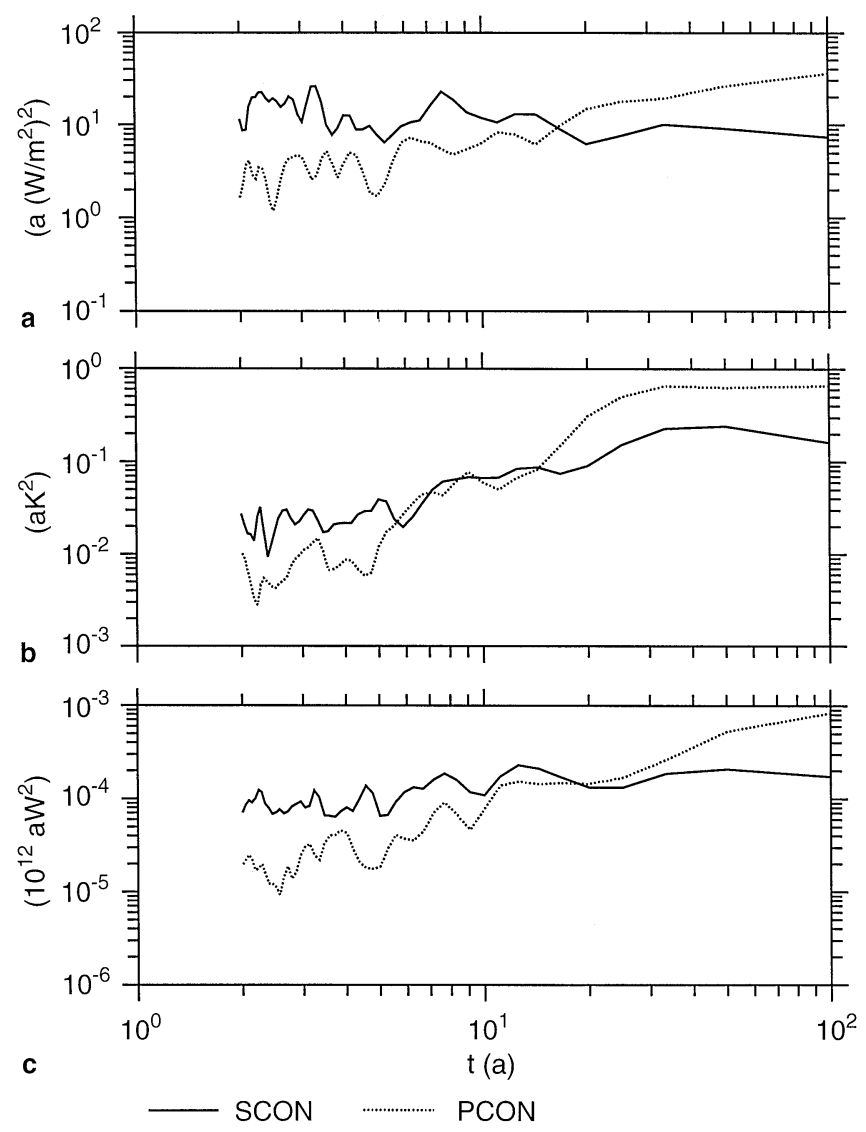

Fig. 13a-c Spectra of the time series for the North Atlantic displayed in Fig. 12. The variables shown are a heat flux, b oceanic temperature of the uppermost ocean layer, and $\mathbf{c}$ loss of potential energy by convection. The spectra are calculated by means of the autocovariance function using a Hanning window with a maximum lag of $100 \mathrm{y}$

depend on the choice of the weighting parameter $g$ of Eq. (1) and the length of the ocean-only periods (Sect. 2.4; for details see Voss 1996). The quasi-equilibrium state of the coupled model is affected by the different determination of the oceanic forcing of the periodically synchronously and the purely synchronously coupled model (see VS). As confirmed by the comparison of the mean states in Sects. 4.2 and 4.3, the possible differences between these mean states due to the changed variability appear to be of minor importance.

\section{Reproduction of climate changes}

\subsection{Transient behaviour}

In this section the response of both model versions to an increase of the atmospheric $\mathrm{CO}_{2}$ concentration is analyzed. The $\mathrm{CO}_{2}$ content of the atmosphere follows the first 60 years IPCC "Business as Usual" scenario A (Houghton et al. 1990) until $\mathrm{CO}_{2}$ doubling is reached. In the following years the $\mathrm{CO}_{2}$ concentration 

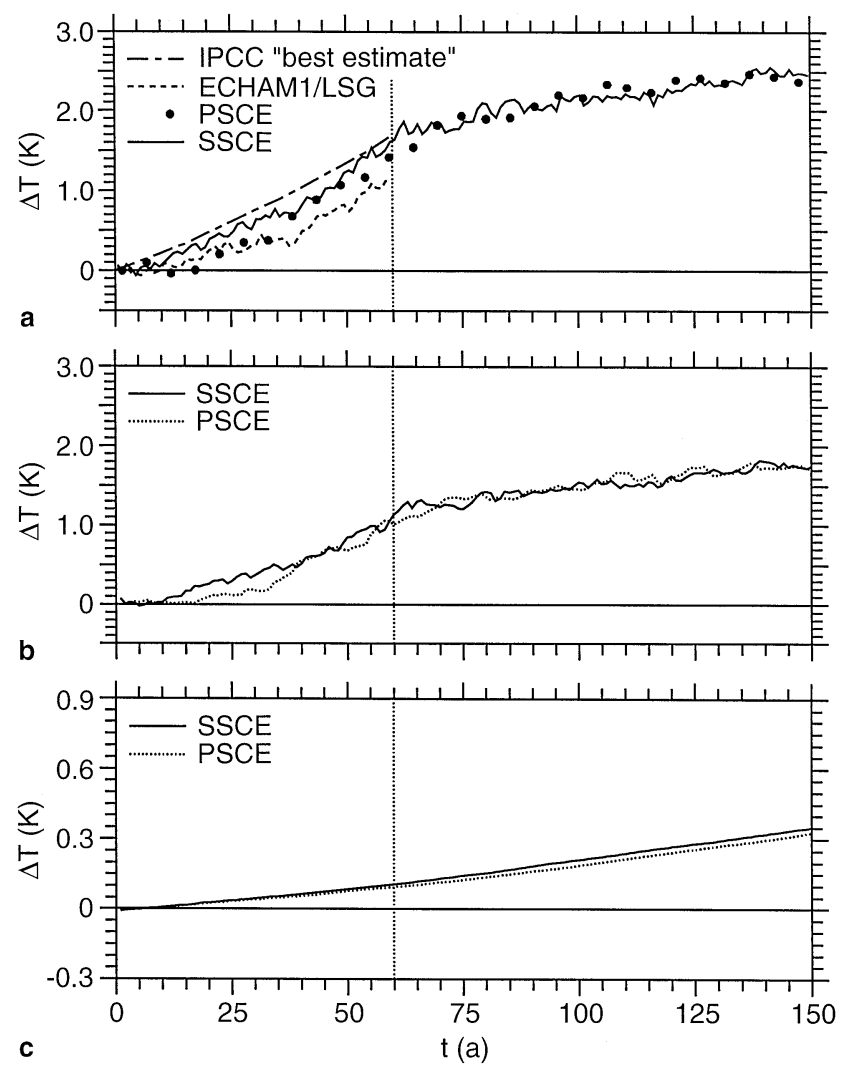

Fig. 14a-c Response of the a global-mean near-surface air temperature, $\mathbf{b}$ the global-mean oceanic temperatures of the uppermost ocean layer and $\mathbf{c}$ of the model layer centred in $2000 \mathrm{~m}$ depth. The means of the first decade of the experiment SCON are subtracted. In addition in a the corresponding estimate of the IPCC (Houghton et al. 1990) and the corresponding experiment of the ECHAM1/LSG AOGCM (Cubasch et al. 1992) are shown

remains constant (see also Sect. 3, Fig. 2). The synchronously (SSCE) and the periodically synchronously (PSCE) coupled integrations are compared to the averages of the first decade of the synchronously coupled simulation with constant $\mathrm{CO}_{2}$ concentration SCON.

In both climate-change simulations the globally averaged near-surface air temperature rises approximately $1.5 \mathrm{~K}$ until the $\mathrm{CO}_{2}$ doubling is reached after $60 \mathrm{y}$ (Fig. 14a). The averages over the last 12 months of the synchronously coupled periods are considered for the experiment PSCE. Particularly in the experiment PSCE, the model response of the first decades is weaker than in the "best estimate" published by the IPCC (Houghton et al. 1990) which was computed by means of a box-diffusion-upwelling model. Two reasons account for this: the cold start effect (Hasselmann et al. 1993) and the delay due to the phase error of the periodically synchronous coupling technique (VS). The latter reason also explains, why the response of PSCE is initially weaker than the response of SSCE. In order to calculate the fluxes, only information of previously computed synchronously coupled periods are used. De- velopments of atmosphere-ocean fluxes during the ocean-only periods using, for instance, temporal derivatives of the atmosphere-ocean fluxes are not taken into account (see Sect. 2.4). At the time of the $\mathrm{CO}_{2}$ doubling the response of both integrations, PSCE and $\mathrm{SSCE}$, is stronger than in the corresponding scenario A integration performed with the previous version of the coupled model (ECHAM1/LSG; Cubasch et al. 1992).

Cubasch et al. (1994) performed a set of scenario A integrations with the ECHAM1/LSG model. The objective of this study was to estimate the spread of the global warming simulations by means of four $50-y$ integrations (one realization consists of the first 50 years of the ECHAM1/LSG integration displayed in Fig. 14a). The four synchronously coupled model runs differ from each other only by the different initial conditions. The time series of this set of simulations show a spread of $0.4 \mathrm{~K}$ during the last decade (41-50). Assuming that the spread of such experiments performed with the present model version (ECHAM3/LSG) is of a similar magnitude, the differences in the response between the experiments SSCE and PSCE are small. The largest differences of about $0.3 \mathrm{~K}$ are reached during the initial period of the experiments. During the period 41-50, for instance, the differences are smaller than $0.1 \mathrm{~K}$.

In spite of the constant $\mathrm{CO}_{2}$ concentration after year 60 , the near-surface air temperature increases further by $0.9 \mathrm{~K}$ up to $2.4 \mathrm{~K}$ after $150 \mathrm{y}$. This warming is stronger than the expected residual climate drift. The corresponding runs with constant $\mathrm{CO}_{2}$ concentration SCON and PCON exhibit a warming of $0.4 \mathrm{~K}$ during the first 150 y (Fig. 3a). Assuming that the climatechange integrations underlie a similar trend, the warming of approximately $0.9 \mathrm{~K}$ between year 60 and year 150 can only partly (by less than $30 \%$ ) be caused by the model drift. One reason of the further increase are adjustment processes in the ocean which last decades to centuries.

The temperature of the ocean shows a distinct reduction of the warming with increasing depth. In the uppermost ocean layer $(25 \mathrm{~m})$, for instance, both climate-change experiments exhibit an increase of 1.7 $\mathrm{K}$ (Fig. 14b). At $2000 \mathrm{~m}$ depth the increase is $0.35 \mathrm{~K}$, which is only about $20 \%$ of the rate for the uppermost ocean layer (Fig. 14c). A part of this warming may be due to the model drift. The temperatures of the simulations SCON and PCON increase $0.3 \mathrm{~K}$ in $25 \mathrm{~m}$ and $0.18 \mathrm{~K}$ in $2000 \mathrm{~m}$ during the first 150 years (Fig. $3 b+c)$.

\subsection{The pattern}

In the following the spatial pattern of the climate change is investigated. The results of the climatechange experiments are compared to the average of the 
$\operatorname{SSCE}(51-60)$ - SCON (1-10)

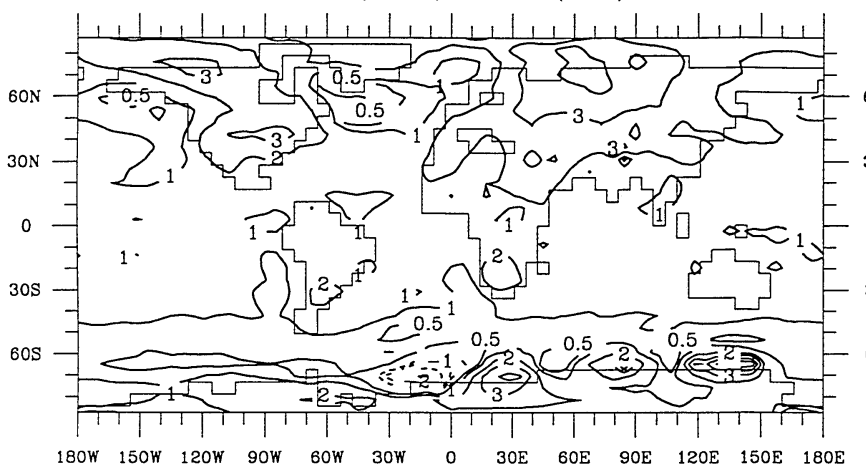

SSCE (141-150) - SCON (1-10)

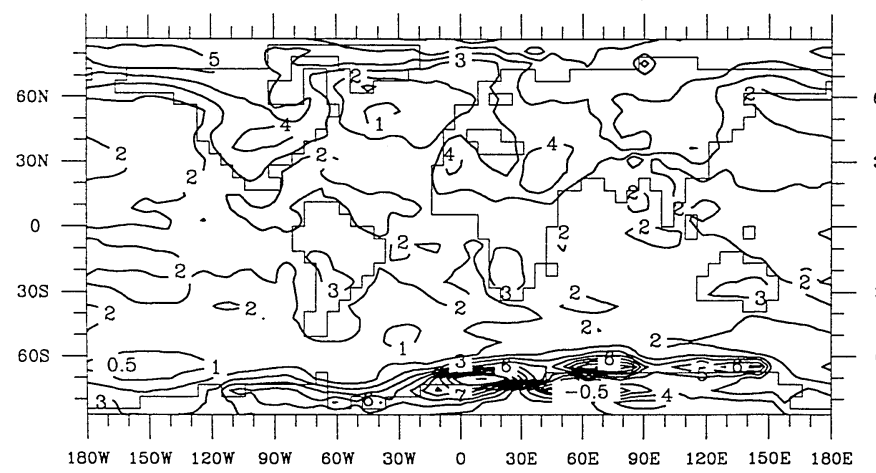

Fig. 15 The changes of the near-surface air temperature of the experiment SSCE (left column) related to the first decade of the experiment SCON and the deviations between the experiments PSCE* and SSCE (right-upper panel), and the standard deviations of

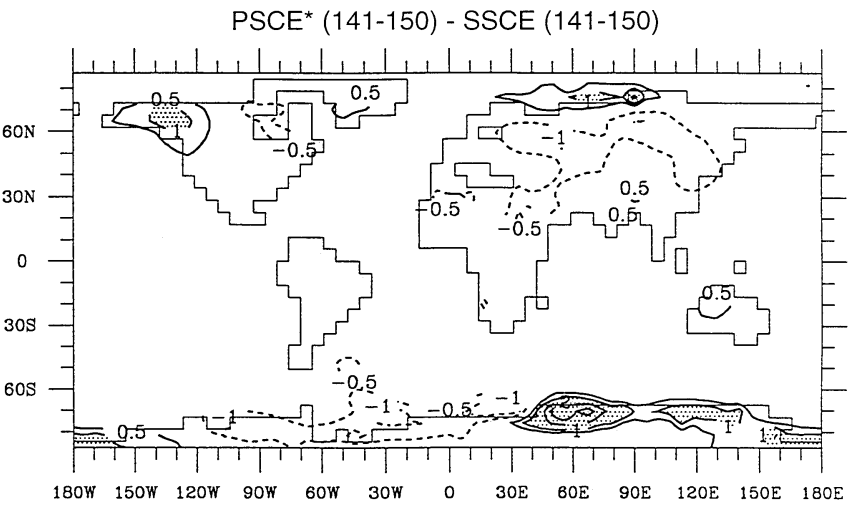

$\sigma(S S C E)$

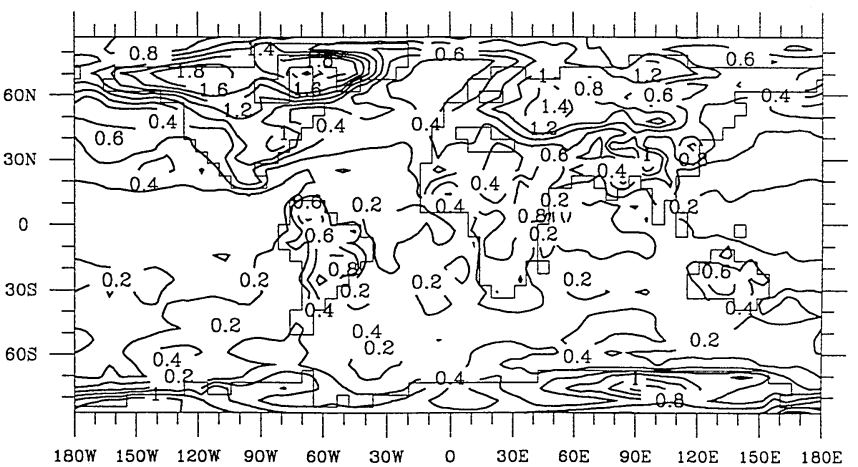

the annual means of the experiment SCON (right-bottom panel). Contours for differences: $\pm 0.5, \pm 1, \pm 2, \pm 3, \pm 4, \pm 5, \pm 6$, $\pm 7, \pm 8, \pm 9, \pm 10 \mathrm{~K}$. Contour interval for standard deviations: $0.2 \mathrm{~K}$

that the anomalous weak warming over the North Atlantic is connected to a weakening of the thermohaline circulation. In the upper ocean of the middle and northern parts of the North Atlantic the temperature increases, whereas the salinity decreases due to an increase of precipitation. As a result the stratification of the ocean becomes more stable, the convection in this part of the ocean decreases, and the mixed layer becomes shallower, especially in winter. In addition the salinity of the subtropical upwelling region increases due to stronger evaporation. Caused by the weakening of the thermohaline circulation, a smaller amount of heat is transported northward.

In the following the atmospheric mean state at the end of the climate-change experiments is analyzed. In order to examine an atmospheric data set of the periodically synchronously coupled model, which is reliable in the statistical sense, a period of several decades has to be considered. Since in the integrations SSCE and PSCE the climate changes throughout the full simulation period (see Fig. 14), we chose another way. The synchronously coupled integration PSCE* starts from the state which is reached by the periodically synchronously coupled run PSCE at the end of year 140 and simulates the period 141-150. Therefore, two atmospheric data sets of the same size are available. This 
makes the comparison more reliable, whereas in the experiment PSCE only two synchronously coupled periods (i.e. two full annual cycles of atmospheric data) have been computed during the period 141-150. The experiments PSCE and PSCE* produce a nearly identical state of the ocean during this period. Deviations, which occur, for example, in the simulations with constant $\mathrm{CO}_{2}$ concentration SCON and PCON at the Antarctic sea-ice edge, do not take effect in the short synchronously coupled integration PSCE*. The deviations between the runs SSCE and PSCE* are compared to the standard deviations which were computed from the annual or seasonal means of the experiment SSCE for the period 141-150.

The largest differences of the near-surface air temperature between the runs SSCE and PSCE* occur in high latitudes (Fig. 15, right column). At the Antarctic continent a maximum with an overestimation of $2 \mathrm{~K}$ in the experiment PSCE* is obtained. Except for two locations in the vicinity of the Antarctic continent the deviations are smaller or in the same range as the standard deviations. The satisfactory agreement is also reflected by a high pattern correlation of 0.95 between both response patterns.

In the free atmosphere the familiar climate-change signal with a warming of the troposphere and a cooling
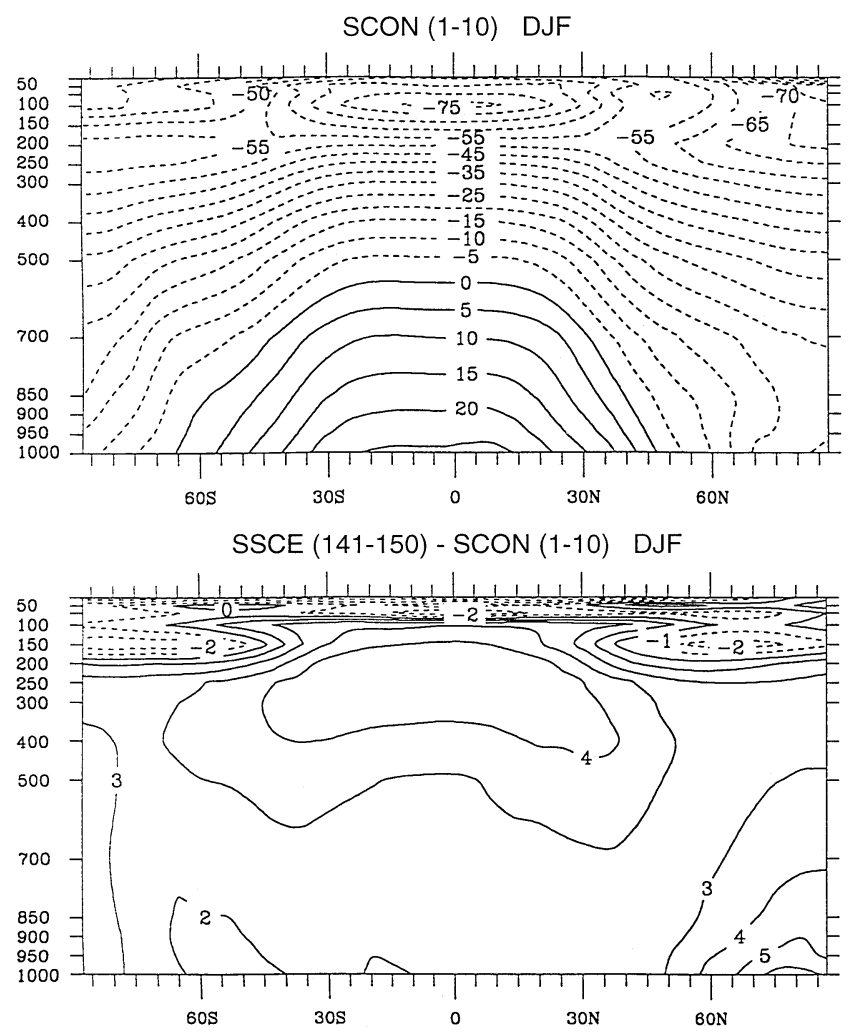

Fig. 16 Zonal-mean temperature of DJF for the first decade of the experiment SCON (left-upper panel; contour interval: $5{ }^{\circ} \mathrm{C}$ ), the differences between the experiments SSCE and SCON (left-bottom panel; contour interval: $1 \mathrm{~K})$, the differences between the experiments of the stratosphere can be observed. The zonal-mean temperature for the season December, January, and February (DJF; Fig. 16, left column), for example, exhibits the maxima of warming in the upper tropical troposphere $(4.9 \mathrm{~K})$ and in the lower layers of the high latitudes of the winter hemisphere $(6.4 \mathrm{~K})$. The differences between the runs SSCE and PSCE* reach values up to $2.6 \mathrm{~K}$ in the polar stratosphere and $-1.1 \mathrm{~K}$ in the tropical stratosphere (Fig. 16, right column). The regions of large differences are characterized by high variability: the standard deviations of the run SSCE are of the same order of magnitude as the differences.

The changes of the temperature distribution result in changes of the atmospheric circulation and the hydrological cycle. The atmospheric circulation described by variables like mean sea level pressure, zonal wind, and meridional mass stream function show a similar good agreement of both simulations as presented for the atmospheric temperature.

A evaluation of the changes in the hydrological cycle is adversely affected by high variability of the concerned variables. Therefore, the response of precipitation and evaporation is investigated using decadal means of the zonal averages (Fig. 17). The changes are related to the averages of the first decade of the run SCON. In order to estimate the variability, the range
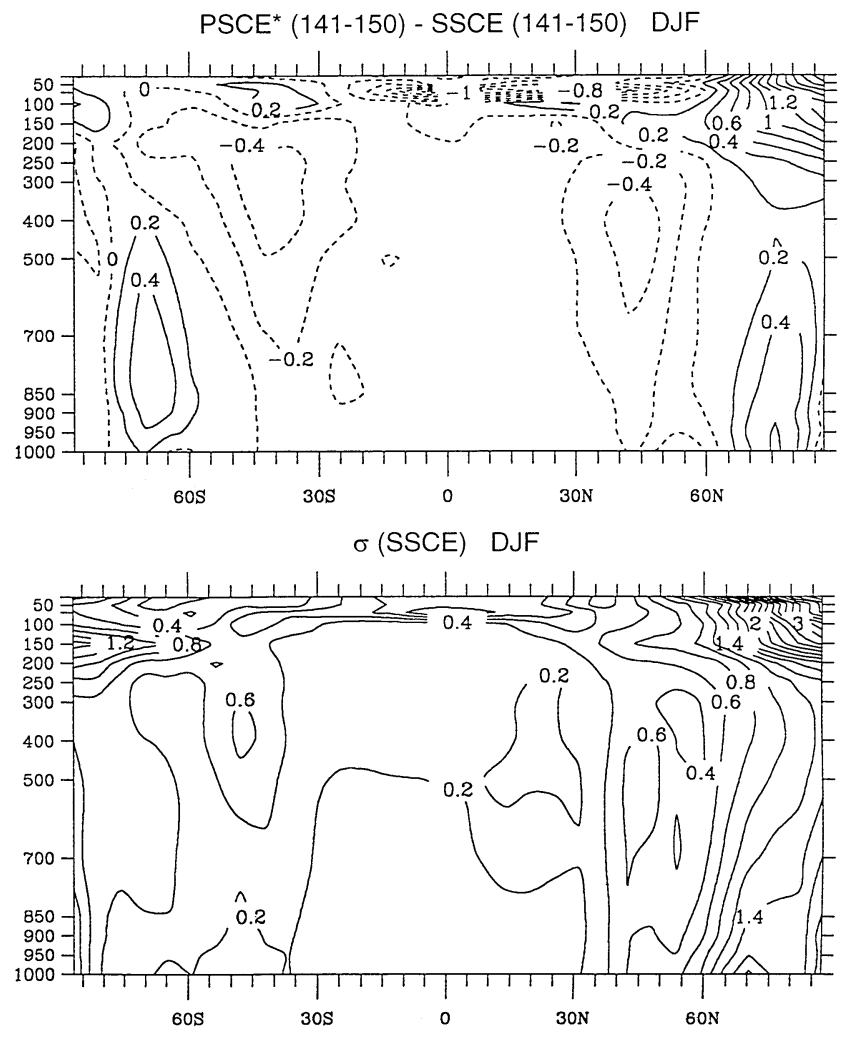

PSCE* and SSCE (right-upper panel; contour interval: $0.2 \mathrm{~K}$ ) and the standard deviations of the seasonal means for the period 141- 150 of the experiment SSCE (right-bottom panel; contour interval: $0.2 \mathrm{~K})$ 
within two standard deviations of the linearly detrended decadal means of the first $150 \mathrm{y}$ of the run SCON is shaded.

The difference, precipitation minus evaporation, mainly determines the fresh-water flux into the ocean and the soil. In the zonal mean, evaporation exceeds precipitation only in the subtropics, and especially, over the oceanic parts of these latitude belts a large amount of water vapour is transferred into the atmosphere (Fig. 17a). This feature can be seen in the syn- chronously coupled simulation with fixed present-day $\mathrm{CO}_{2}$ concentration SCON, as well as in both climatechange experiments SSCE and PSCE*. Nevertheless, the differences between the last decade of the climatechange experiments and the first decade of the experiment SCON show an enhanced amplitude due to the increase of the $\mathrm{CO}_{2}$ concentration (Fig. 17b).

With the exception of the subtropical high-pressure belts, the zonally averaged precipitation of the years 141-150 increases compared to the first decade of the
Fig. 17a-d Zonal-mean distributions for a precipitation minus evaporation. The anomalies of $\mathbf{b}$ precipitation and evaporation, $\mathbf{c}$ precipitation, and d evaporation are related to the means of the first decade of the experiment SCON. The range, which is smaller than two standard deviations of the linear detrended decadal means of the first $150 \mathrm{y}$ of the run SCON, is shaded

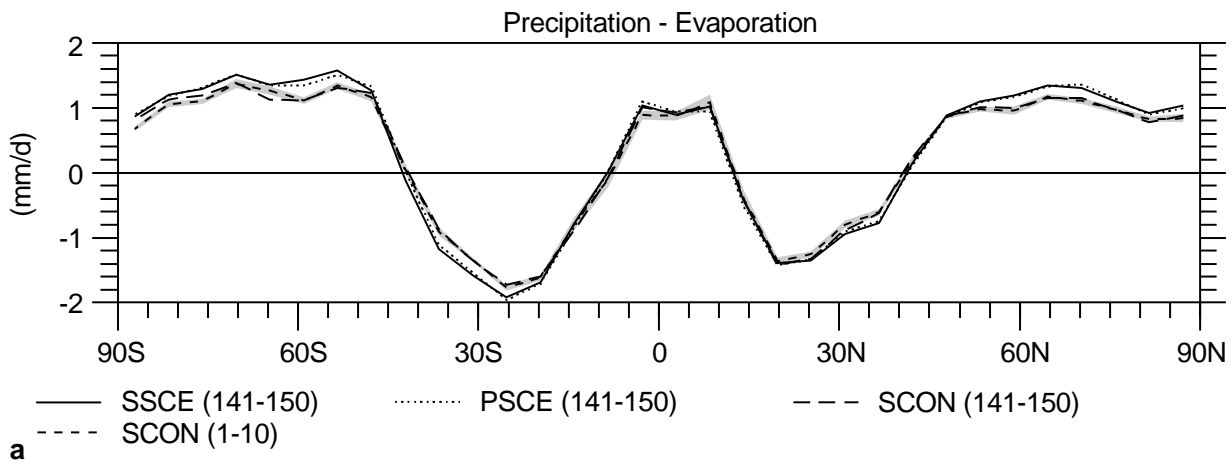

Dif. Precipitation - Evaporation

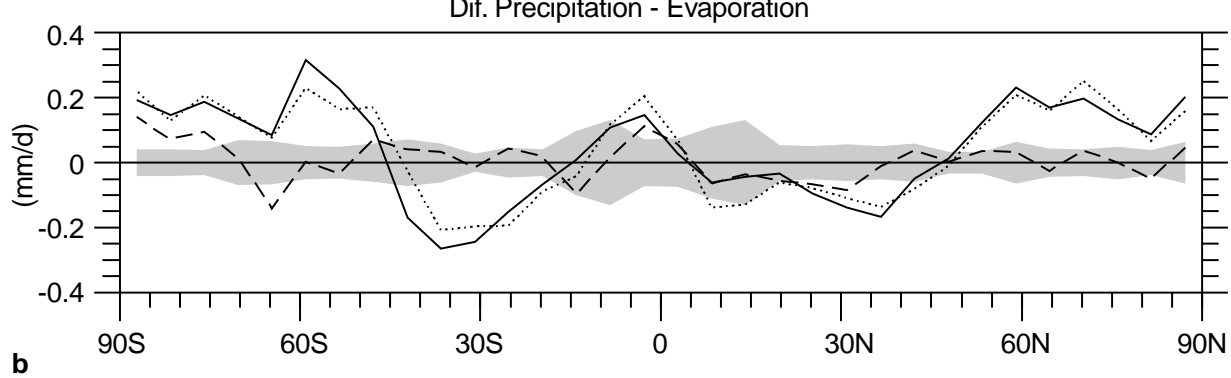

Dif. Precipitation

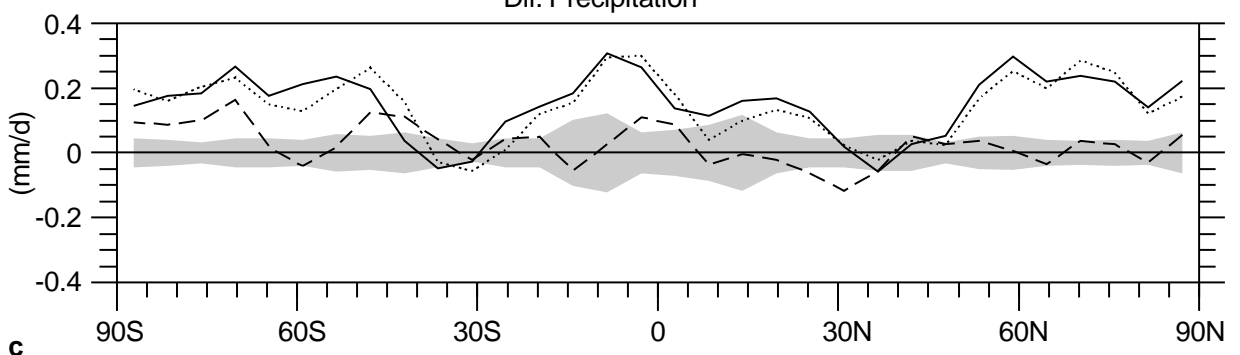

Dif. Evaporation

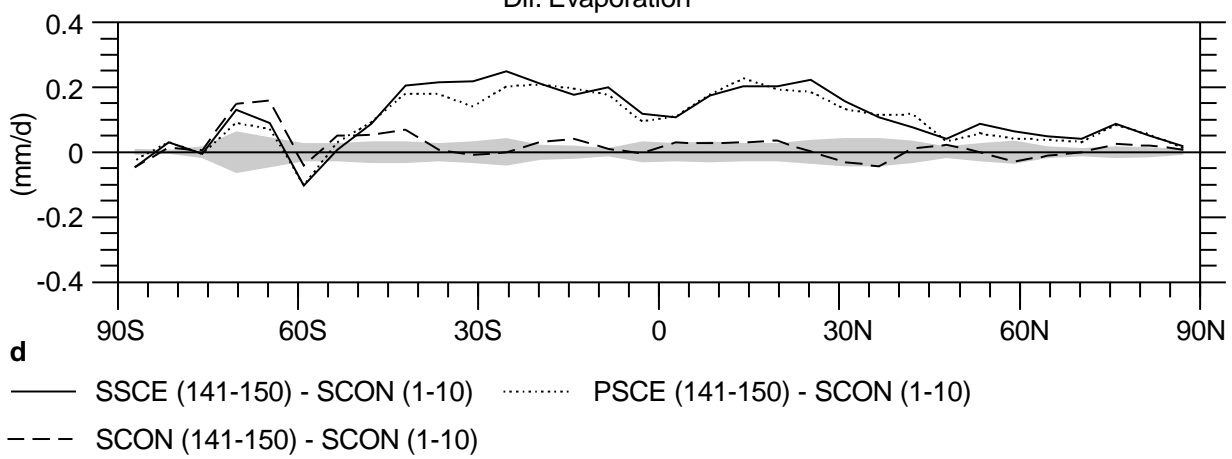



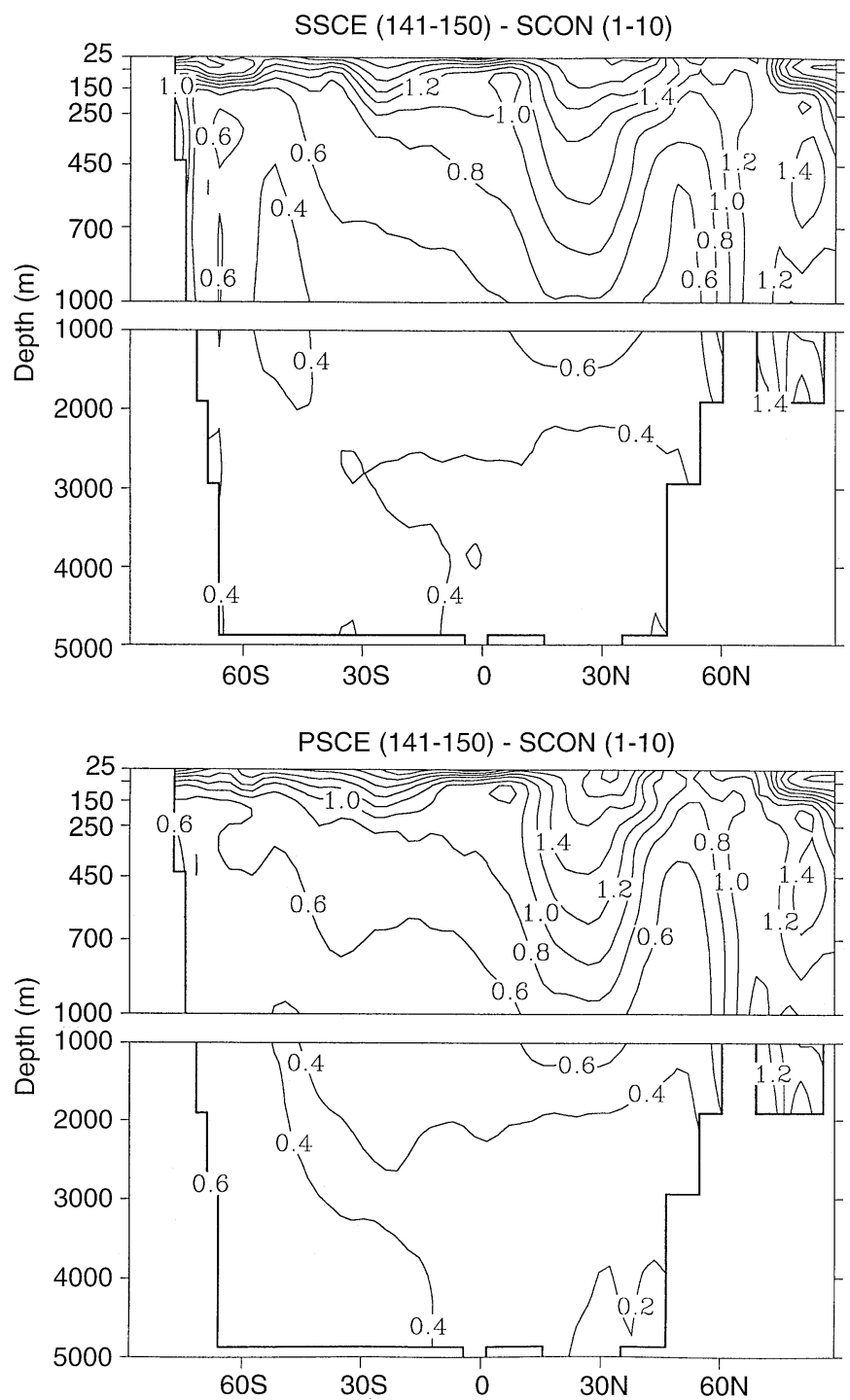

Fig. 18 Anomalies of the zonal-mean ocean temperatures (K) for the Atlantic. The values of the period 141-150 of the experiments SSCE (upper panel) and PSCE (bottom panel), respectively, are related to the means of the first decade of the experiment SCON. Contour interval: $0.2 \mathrm{~K}$

run SCON and exceeds the two standard deviation range of the run SCON (Fig. 17c). The evaporation increases in nearly all latitudes (Fig. 17d). Only at a latitude belt around $60^{\circ} \mathrm{S}$ is the evaporation reduced. The zonal means of the run SCON for the years 141-150 show a similar tendency in this region. Therefore, this behaviour can mainly be attributed to the model trend and not to the increase of the $\mathrm{CO}_{2}$ concentration.

Due to the increased $\mathrm{CO}_{2}$ concentration the subtropical parts of the atmosphere take up more water vapour as indicated by the difference of precipitation minus evaporation in Fig. 17b. In the intertropical convergence zone (ITCZ), on the other hand, the in- crease of precipitation is larger than the increase of evaporation. In the mid latitudes the increase of the difference, precipitation minus evaporation, exceeds the two standard deviation limit and reaches values of more than $0.2 \mathrm{~mm} / \mathrm{d}$. The differences between both climate-change experiments, PSCE and SSCE, for precipitation, evaporation and their difference are considerably smaller than the climate-change signal.

As can be observed in Fig. 14, the warming of the upper ocean due to the increased $\mathrm{CO}_{2}$ concentration penetrates into the deep ocean. The heat transport into the deeper layers is strongest in regions with strong convection, i.e., in the North Atlantic and in the Southern Ocean. As an example, the zonal-mean temperature response of the Atlantic is shown in Fig. 18. The strongest warming occurs in the upper ocean. Local maxima of the warming occur in the subtropics which are anyway characterized by high temperatures. In the polar regions the increase of the temperature is partly caused by the reduction of sea-ice coverage. In the upper layers of the North Atlantic a relatively small increase of the temperature can be seen which is caused by the strong heat transport into the deep ocean and the reduced internal heat transport from lower latitudes (see discussion of near-surface air temperature response earlier). In the deep ocean the warming of the Atlantic sector of the Arctic is $1.4 \mathrm{~K}$ higher than in the other regions of the Atlantic. The penetration of warmer water into deeper layers, but with a smaller amplitude, also takes place in the Atlantic sector of the Southern Ocean. In this region the experiment SSCE exhibits slightly higher temperatures, but in general the agreement of the temperature pattern of the Atlantic between both model version is satisfactory.

The climate-change patterns of the experiments SSCE and PSCE are in good agreement with corresponding greenhouse-gas experiments performed with other AOGCMs (e.g. Washington and Meehl 1989; Cubasch et al. 1992; Houghton et al. 1992; Murphy and Mitchell 1995).

\section{Conclusions}

The periodically synchronous coupling scheme has been applied to the AOGCM ECHAM3/LSG. Due to temporary switching off of the atmospheric component this scheme saves computer resources compared to the synchronous coupling where both model components are integrated over the full simulation period. Since most AOGCMs of the present-day generation are coupled synchronously and the computer resources are a limiting factor of many experiments, the reduction of computer requirements is of importance. The applied scheme was developed by means of a simple model (see $\mathrm{SV}$ and VS) and has been tested in a more comprehensive model. The length of the ocean-only periods is 
chosen so that $70 \%$ of the computer time is saved in the periodically synchronously coupled model version of ECHAM3/LSG. When starting our integrations with ECHAM3/LSG, we have been rather careful in the choice of the length of the ocean-only periods. In view of our results, we also might have chosen somewhat longer ocean-only periods.

To test the new coupling scheme two pairs of synchronously and periodically synchronously coupled integrations have been performed. In one set of experiments the atmospheric $\mathrm{CO}_{2}$ concentration has been fixed at the present-day value and in the other case the $\mathrm{CO}_{2}$ content gradually increases until $\mathrm{CO}_{2}$ doubling is reached after $60 \mathrm{y}$ and remains fixed for the following years.

The examination of these two cases shows:

1. A good agreement of the mean states, i.e. in general the deviations of the periodically synchronously coupled experiments are smaller or the same order of magnitude than the standard deviations of the respective annual or seasonal means of the synchronously coupled reference runs. Only in small areas at the vicinity of the sea-ice margin are the differences larger.

2. Changes in the spectral properties, since in the periodically synchronously coupled model the annual means and annual cycles of the ocean forcing remain constant during the ocean-only periods. This feature of the scheme causes an underestimation of the short-term variability. On the other hand, the weighting procedure of the annual-mean atmosphere-ocean fluxes results in an overestimation of the long-term fluctuations. Due to the weighting a memory is implemented. Perturbations which are strong enough to get into this memory are preserved for a long period (see also Fig. 5 of VS).

3. A slightly delayed response of the periodically synchronously coupled model which is due to the weighting procedure for the atmosphere-ocean fluxes. The climate-change patterns of ocean and atmosphere in both model versions exhibit the same features.

With the chosen length of the synchronously coupled and ocean-only periods, phenomena on short time scales, i.e., of the order of the period length of the ocean-only periods, like the El Niño - Southern Oscillation phenomenon, are not adequately resolved. Signals with a strong amplitude, as in the described experiments with increasing $\mathrm{CO}_{2}$ concentration, are sufficiently reproduced. The deviations to the corresponding synchronously coupled experiments are of same order of magnitude as many other uncertainties. For example, changes of the vegetation or the ice sheets which both influence the water budget and the albedo are not considered in the model.

The largest differences occur in the vicinity of the Antarctic sea ice. Due to the non-linearities like ice-albedo feedback and ocean convection, which are important physical processes in this region, small changes in the sea-ice coverage could lead to large differences, for example, in the near-surface air temperature, heat flux or evaporation. As the Antarctic sea ice in the ECHAM3/LSG model is characterized by high variability and a strong drift, problems like these could be expected in this region.

The residual climate drift in both model versions exhibits nearly the same amount which points to a possible application of the periodically synchronous coupling technique, as this undesirable drift is also present in other AOGCMs (e.g. Murphy 1995; Manabe and Stouffer 1996; von Storch et al. 1997). With this relatively "cheap" coupling method it is possible to perform some tests in order to investigate the drift and its causes which would be a rather expensive investigation for synchronously coupled models. Another interesting application is the investigation of long-term changes and new quasi-equilibrium states due to changes of external parameter (e.g. solar irradiance or $\mathrm{CO}_{2}$ concentration).

Hitherto not much experience with periodically synchronously coupled AOGCMs exists. The model integrations presented are an important step in the development of this coupling strategy. The simple formulation of the calculation of the atmosphere-ocean fluxes during the ocean-only periods is independent of time and space and needs only a relatively small data bank. As shown in our study the formulation leads to reliable results for the simulation of a climate state as well as for the climate change. The latter is confirmed by a study of Schiller et al. (1997) who investigated the response of the climate system to an additional fresh-water input into the North Atlantic. They used the periodically synchronously coupled ECHAM3/LSG and performed some tests with the synchronously coupled version for comparison. Nevertheless, tests with other atmospheric and oceanic model components with different formulations of the atmosphere-ocean interaction are desirable.

A further development for simulations with an expected slowly changing climate or without climate change seems to be possible. In order to extend the ocean-only periods a feedback term for the atmosphere during the ocean-only periods should be introduced. This could be done by a relaxation to the just-obtained climate state. With this approach the possible drift of the ocean during long ocean-only periods due to the missing feedback of the atmospheric model could be reduced. With longer ocean-only periods the reduction of computer time increases. The variability of the model could also be improved. This could be realized by an extension of the synchronously coupled periods in slowly changing systems. Due to the longer simulation of the atmosphere an improved statistical description of the variability of the atmosphere-ocean fluxes could be obtained. This leads to a better estimate of the forcing during the ocean-only periods. However, one should keep in mind that a longer synchronously coupled period also means a much longer ocean-only 
period, so that the saving of the computer time should be the same.

Acknowledgements The authors would like to thank U. Mikolajewicz for many helpful discussions. We thank the staff of the Deutsches Klimarechenzentrum, the Meteorologisches Institut der Universität Hamburg and the Max-Planck-Institut für Meteorologie for their support. The work was supported by grants from the climate program of the European Union (EPOC-0003$\mathrm{C}(\mathrm{MB})$ and EV5V-CT92-0123) and by the Bundesministerium für Bildung und Forschung. The ECWMF analyses were used by permission of the ECMWF and the Deutscher Wetterdienst.

\section{References}

Arakawa A, Lamb VR (1977) Computational design of the basic dynamical processes of the UCLA general circulation model. Methods Comp Phys 17:173-265

Broecker WS (1991) The great ocean conveyor. Oceanography 4:79-89

Cubasch U, Hasselmann K, Höck H, Maier-Reimer E, Mikolajewicz U, Santer BD, Sausen R (1992) Time-dependent greenhouse warming computations with a coupled ocean-atmosphere model. Clim Dyn 8: 55-69

Cubasch U, Santer BD, Hellbach A, Hegerl G, Höck H, MaierReimer E, Mikolajewicz U, Stössel A, Voss R (1994) Monte Carlo climate change forecasts with a global coupled ocean-atmosphere model. Clim Dyn 10:1-19

Gordon AL (1986) Interocean exchange of thermocline water. J Geophys Res 91: 5037-5046

Hasselmann K (1976) Stochastic climate models. Part I: theory. Tellus 28:473-485

Hasselmann K, Sausen R, Maier-Reimer E, Voss R (1993) On the cold start problem in transient simulations with coupled atmosphere-ocean models. Clim Dyn 9:53-61

Hegerl G, Hasselmann K, Cubasch U, Mitchell JFB, Roeckner E, Voss R, Waszkewitz J (1997) Multi-fingerprint detection and attribution analysis of greenhouse gas, greenhouse gas-plus-aerosol and solar forced climate change. Clim Dyn 13:613-634.

Houghton JT, Jenkins GJ, Ephraums JJ (eds) (1990) Climate change: the IPCC scientific assessment. Cambridge University Press, Cambridge, UK

Houghton JT, Callander BA, Varney JJ (eds) (1992) Climate change 1992: the supplementary report to the IPCC scientific assessment. Cambridge University Press, Cambridge

Levitus S (1982) Climatological atlas of the world ocean. NOAA Prof Pap 13, 173 pp

Lunkeit F, Sausen R, Oberhuber JM (1996) Climate simulations with the global coupled atmosphere-ocean model ECHAM2/ OPYC. Part I: present-day climate and ENSO events. Clim Dyn $12: 195-212$
Maier-Reimer E, Mikolajewicz U, Hasselmann K (1993) Mean circulation of the Hamburg LSG OGCM and its sensitivity to the thermohaline surface forcing. J Phys Oceanogr 23:731-757

Manabe S, Stouffer RJ (1994) Multiple-century response of a coupled ocean-atmosphere model to an increase of the atmospheric carbon dioxide. J Clim 7:5-23

Manabe S, Stouffer RJ (1996) Low-frequency variability of surface air temperature in a 1000-year integration of a coupled atmosphere-ocean-land surface model. J Clim 9:376-393

Mikolajewicz U, Cubasch U, Hegerl G, Höck H, Maier-Reimer E, Santer BD, Schultz S (1994) Changes in oceanic circulation of the North Atlantic as a result of an increase in atmospheric greenhouse gas concentration. ICES Mar Sci-Symp 198:292-296

Murphy JM (1995) Transient response of the Hadley centre coupled ocean-atmosphere model to increasing carbon dioxide. Part I: control climate and flux adjustment. J Clim 8:36-56

Murphy JM, Mitchell JFB (1995) Transient response of the Hadley centre coupled ocean-atmosphere model to increasing carbon dioxide. Part II: spatial and temporal structure of response. J Clim $8: 57-80$

Roeckner E, Arpe K, Bengtsson L, Brinkop S, Dömenil L, Esch M, Kirk E, Lunkeit F, Ponater M, Rockel B, Sausen R, Schlese U, Schubert S, Windelband M (1992) Simulation of the present-day climate with the ECHAM model: impact of the model physics and resolution. Max-Planck-Institut für Meteorologie, Hamburg, Rep 93

Sausen R, Voss R (1996) Techniques for asynchronous and periodically synchronous coupling of atmosphere and ocean models. Part I: general strategy and application to the cyclo-stationary case. Clim Dyn 12:313-323

Sausen R, Barthel K, Hasselmann K (1988) Coupled oceanatmosphere models with flux correction. Clim Dyn 2:145-163

Sausen R, Schubert S, Dömenil L (1994) A model of the river runoff for the use in coupled atmosphere-ocean models. J Hydrology $155: 337-352$

Schiller A, Mikolajewicz U, Voss R (1997) The stability of the North Atlantic thermohaline circulation in a coupled ocean-atmosphere general circulation model. Clim Dyn 13:325-347

Schmitz WJ (1995) On the interbasin-scale thermohaline circulation. Rev Geophys 33:151-173

von Storch J-S, Kharin V, Cubasch U, Hegerl G, Schriever D, von Storch H, Zorita E (1997) A 1260-year control integration with the coupled ECHAM1/LSG general circulation model. J Clim 10:1525-1543

Timmermann A, Latif M, Voss R, Grötzner A (1998) A mechanism for interdecadal North Atlantic variability. J Clim (accepted)

Voss R (1996) Entwicklung eines Kopplungsverfahrens zur Reduzierung der Rechenzeit von Atmosphäre-Ozean-Modellen. Max-Planck-Institut für Meteorologie, Hamburg, Examensarbeit 38 (ISSN 0938-5177), 123 pp

Voss R, Sausen R (1996) Techniques for asynchronous and periodically synchronous coupling of atmosphere and ocean models. Part II: impact of variability. Clim Dyn 12:605-614

Washington WM, Meehl GA (1989) Climate sensitivity due to increased $\mathrm{CO}_{2}$ : experiments with a coupled atmosphere and ocean general circulation model. Clim Dyn 4:1-38 